\title{
Inhibition of the anti-apoptotic protein MCL-1 severely suppresses human hematopoiesis
}

\author{
Sheila Bohler, ${ }^{1,2}$ Sehar Afreen, ${ }^{1}$ Juncal Fernandez-Orth, ${ }^{1}$ Eva-Maria \\ Demmerath, ${ }^{1}$ Christian Molnar, ${ }^{1,2,3}$ Ying Wu, ${ }^{1,2}$ Julia Miriam Weiss, ${ }^{1}$ Venugopal \\ Rao Mittapalli, ${ }^{1}$ Lukas Konstantinidis, ${ }^{4}$ Hagen Schmal, ${ }^{4}$ Mirjam Kunze ${ }^{5}$ and \\ Miriam Erlacher ${ }^{1,6,7}$
}

Haematologica 2021

Volume 106(12):3136-3148

\begin{abstract}
${ }^{1}$ Department of Pediatrics and Adolescent Medicine, Division of Pediatric Hematology and Oncology, University Medical Center Freiburg, Faculty of Medicine, University of Freiburg, Freiburg; ' $F$ Faculty of Biology, University of Freiburg, Freiburg; ${ }^{3}$ Spemann Graduate School of Biology and Medicine (SGBM), University of Freiburg, Freiburg; ${ }^{4}$ Department of Orthopedics and Trauma Surgery, Medical Center, Faculty of Medicine, Albert-Ludwigs-University of Freiburg, Freiburg; ${ }^{5}$ Department of Obstetrics and Gynecology, University Medical Center Freiburg, Faculty of Medicine, University of Freiburg, Freiburg; ${ }^{6}$ German Cancer Consortium (DKTK), Freiburg, and ${ }^{7}$ German Cancer Research Center (DKFZ), Heidelberg, Germany
\end{abstract}

\section{ABSTRACT}

$\mathrm{B}$ H3-mimetics inhibiting anti-apoptotic BCL-2 proteins represent a novel and promising class of antitumor drugs. While the BCL-2 inhibitor venetoclax is already approved by the Food and Drug Administration, BCL-XL and MCL-1 inhibitors are currently in early clinical trials. To predict side effects of therapeutic MCL-1 inhibition on the human hematopoietic system, we used RNA interference and the small molecule inhibitor S63845 on cord blood-derived CD34 ${ }^{+}$cells. Both approaches resulted in almost complete depletion of human hematopoietic stem and progenitor cells. As a consequence, maturation into the different hematopoietic lineages was severely restricted and $\mathrm{CD} 34^{+}$cells expressing MCL-1 shRNA showed a very limited engraftment potential upon xenotransplantation. In contrast, mature blood cells survived normally in the absence of MCL-1. Combined inhibition of MCL-1 and BCL-XL resulted in synergistic effects with relevant loss of colony-forming hematopoietic stem and progenitor cells already at inhibitor concen-

\section{Correspondence:}

MIRIAM ERLACHER

miriam.erlacher@uniklinik-freiburg.de

Received: March 17, 2020.

Accepted: November 6, 2020.

Pre-published: November 26, 2020.

https://doi.org/10.3324/haematol.2020.252130

(C)2021 Ferrata Storti Foundation

Material published in Haematologica is covered by copyright. All rights are reserved to the Ferrata Storti Foundation. Use of published material is allowed under the following terms and conditions:

https://creativecommons.org/licenses/by-nc/4.0/legalcode. Copies of published material are allowed for personal or internal use. Sharing published material for non-commercial purposes is subject to the following conditions:

https://creativecommons.org/licenses/by-nc/4.0/legalcode, sect. 3. Reproducing and sharing published material for commercial purposes is not allowed without permission in writing from the publisher. trations of $0.1 \mu \mathrm{M}$ each, indicating "synthetic lethality" of the two BH3mimetics in the hematopoietic system.

\section{Introduction}

BH3-mimetics represent a novel and very promising group of anticancer drugs, with venetoclax being the first compound approved by the Food and Drug Administration (FDA). ${ }^{1}$ They act by directly inhibiting anti-apoptotic BCL-2 proteins that prevent the intrinsic apoptosis pathway and thereby ensure survival of every human cell. BCL-2 and its homologs BCL-XL, MCL-1, BFL1/A1 and BCL-W bind to and inhibit BAX and BAK, two downstream pro-apoptotic effector BCL-2 proteins which, upon activation, lead to permeabilization of the outer mitochondrial membrane. ${ }^{2}$ As a consequence, cytochrome $\mathrm{c}$ is released into the cytosol, a process regarded as a "point of no return" for the initiation of apoptosis. In the cytosol, cytochrome c together with APAF1 and procaspase 9 molecules form a large complex termed an apoptosome, in which caspase 9 is activated. Caspase 9 then activates the effector caspases 3,6 and 7 which eventually degrade vital cellular structures and execute cell death. This whole process is regulated by upstream pro-apoptotic proteins that also belong to the large BCL-2 family but share only the BH3 (BCL2 homology 3 ) domain with the other members of the anti-apoptotic BCL-2 family. BH3-only proteins are upregulated or activated upon given stress signals and then bind and inhibit the anti-apoptotic BCL-2 proteins. As a consequence, BAX and BAK are released, leading to apoptosis. ${ }^{3}$ As their name indicates, $\mathrm{BH}$-mimetics imitate the mode of action of the $\mathrm{BH} 3$-only proteins. ${ }^{4}$ While BH3-only proteins are tightly regulated and only activated upon lethal stress 
signals, BH3-mimetics are able to bypass this mode of activation.

Similar to BH3-only proteins, every BH3-mimetic available so far has specific binding affinities to one or more anti-apoptotic BCL-2 proteins (Online Supplementary Figure S1A). Navitoclax (ABT-263) $)^{5}$ and its intravenously used precursor drug, $\mathrm{ABT}-737,{ }^{6}$ bind to $\mathrm{BCL}-2, \mathrm{BCL}-\mathrm{XL}$ and BCL-W. The drug showed good efficacy against non-small lung carcinoma and hematologic malignancies.,8 However, its side effects on the hematopoietic system precluded its full clinical exploration and FDA approval. This indicated that a combined inhibition of more than one pro-survival BCL-2 protein might impede survival of healthy body cells. Later, a BCL-2-specific inhibitor called venetoclax (ABT-199) found its way into clinical trials. ${ }^{9}$ Thanks to the much less severe side effects, it was approved by the FDA in 2016 as a second-line treatment for chronic lymphocytic leukemia (CLL) with $17 p$ deletion, and in 2019 for the treatment of all adult CLL and small lymphocytic lymphoma patients. ${ }^{1}$ For acute myeloid leukemia (AML), venetoclax was FDA-approved only in combination with hypomethylating agents. ${ }^{1}$

Unfortunately, as for other cytotoxic drugs, tumor cell resistance poses a major problem to the efficacy of venetoclax. Primary resistance is present when tumor cells require anti-apoptotic BCL-2 proteins other than BCL-2 for survival. Naturally, only lymphocytes ${ }^{10}$ and melanocytes $^{11}$ are dependent on BCL-2 expression, as shown in BCL-2 knockout mice. This might explain why venetoclax is most effective in mature lymphoma while most other tumors show primary resistance. Such primary resistance to venetoclax can also be caused by overexpression of pro-survival proteins other than BCL-2, such as BCL-XL and/or MCL-1. ${ }^{12,13}$ As shown for CLL, these BCL2 homologs can be induced by signals from the tumor microenvironment. ${ }^{14}$ Secondary resistance, in contrast, is acquired by tumor cells to escape previously effective BCL-2 inhibition. Several mechanisms, such as BCL-2 mutations which strongly lower venetoclax affinity, ${ }^{15}$ have been implicated in the development of secondary venetoclax resistance. ${ }^{16}$ Alternatively, BCL-XL and MCL-1 overexpression was noted in relapsed CLL patients who had been previously treated with venetoclax. ${ }^{17,18}$ Therefore, the development and administration of MCL-1/BCL-XL inhibitors are much needed to overcome primary and secondary venetoclax resistance. MCL-1 inhibitors, in particular, are eagerly awaited by oncologists since this protein plays an essential role in many tumor types (e.g., AML, multiple myeloma, non-small cell lung carcinoma). ${ }^{19}$

MCL-1 was first identified during the differentiation of monocytes to macrophages in ML-1, a human myeloid leukemia cell line. ${ }^{20}$ Three isoforms of the gene have been reported; the most abundant anti-apoptotic MCL-1 long $(\mathrm{MCL}-1 \mathrm{~L})^{20}$ and two shorter pro-apoptotic isoforms (MCL1 short, MCL-1 extra short). ${ }^{21,22}$ In addition, a truncated isoform was shown to localize at the mitochondrial matrix where it facilitates mitochondrial fusion and ATP synthesis. ${ }^{23}$ Genetic $\mathrm{Mcl}-1$ deletion in mice revealed its essential role in many tissues, both during embryogenesis and in adult mice. Specifically, constitutive MCL-1 deficiency resulted in peri-implantation embryonic lethality, ${ }^{24}$ while targeted deletion in the fetal hematopoietic system resulted in loss of stem cells. ${ }^{25}$ When one $M c l-1$ allele was deleted in adult mice, hematopoietic stem and progenitor cells (HSPC) were depleted, leading to the death of the animals within 2-3 weeks. ${ }^{26}$ With regard to human HSPC, there is only indirect evidence for the essential role of MCL-1, given by the BH3 profiling method: Mitochondria isolated from human $\mathrm{CD} 34^{+}$cells were highly sensitive to NOXA BH3 peptides, which typically correlated with MCL-1 dependency. ${ }^{27}$

Recently, a potent and specific MCL-1 inhibitor, S63845, was developed. This compound can efficiently kill a variety of tumor cell types such as multiple myeloma, lymphomas, leukemias and primary AML cells as well as to some extent solid cancers. ${ }^{28}$ Treatment of mice with S63845 resulted in only a few side effects in vivo, ${ }^{28}$ which was rather unexpected considering the many roles of MCL-1 during development and for tissue homeostasis. Here, we extended these studies to human cells and focused on the hematopoietic system. Understanding hematotoxicity of novel anticancer drugs is crucial since suppression of hematopoiesis accounts for most treatment-related morbidity and mortality. By using two different shRNA sequences and the MCL-1 inhibitor S63845, we consistently found that MCL-1 expression is essential for the survival of human stem and progenitor cells, especially during early stages of differentiation. In contrast, mature blood cells are less sensitive to MCL-1 inhibition. Of note, combined inhibition of MCL-1 and BCL-XL was synergistic and already low concentrations of both drugs resulted in profound stem and progenitor cell depletion.

\section{Methods}

\section{Lentiviruses}

A pLeGO-hU6 lentiviral vector with huU6 promoter and green fluorescent protein (GFP) expression was used to generate shRNA expressing lentiviruses (Online Supplementary Table S1), ${ }^{29}$ $\mathrm{CD}^{2} 4^{+}$cells were transduced with the lentivirus (2x MOI 10, 24 $\mathrm{h}$ each) and knockdown efficiencies were determined $24 \mathrm{~h}$ later.

\section{Isolation and culture of human CD34+ cells}

Umbilical cord blood and bone marrow were obtained immediately after birth or from patients (age: 44-90 years) undergoing orthopedic surgery, respectively. Informed consent was obtained and the ethics committee approved the study. CD34 ${ }^{+}$cells were isolated (by magnetic activated cell sorting) from mononuclear cells to a purity $>90 \%$. Cells were used either immediately or stored in liquid nitrogen (CS10 freezing medium, Sigma) for later use. Cells were cultured in serum-free StemPro-34 medium supplemented with embryonic stem cell fetal bovine serum (ES$\mathrm{FBS}$ ), penicillin/streptomycin (P/S; Invitrogen), stem cell factor (SCF), FMS-like tyrosine kinase 3 ligand (FLT3L) $(200 \mathrm{ng} / \mathrm{mL}$ each), thrombopoietin (TPO; $100 \mathrm{ng} / \mathrm{mL}$ ) and interleukin 3 (IL-3; $20 \mathrm{ng} / \mathrm{mL}$; Immunotools/Peprotech). Where indicated, the BH3mimetics S63845 (SynMedChem), A-1155463 and ABT-199 (Sellekchem) were added.

\section{Apoptosis assay}

CD34 ${ }^{+}$cells were subjected to cytokine deprivation or treated with etoposide (VP16), tunicamycin, taxol, thapsigargin and brefeldin A (BFA). After 0,24 and 48 h, cells were stained with annexin V (Biolegend) and 7-aminoactinomycin D (7-AAD; Sigma-Aldrich) to detect apoptosis. The percentage of specific apoptosis was calculated as: $100 \mathrm{x}$ (\% living cells under control condition - \% living cells under treatment)/ \% living cells under control condition. Control condition was culture with ES-FBS and cytokines. 


\section{Colony-forming assays and differentiating culture}

One thousand CD34+ cells were seeded in MethoCult SFH4436 medium. After 10-11 days, colony types (identified by light microscopy) and total cell counts were determined. The percentages of HSPC, erythroid and myeloid cells were determined by flow cytometry (Online Supplementary Table S2).

\section{Proliferating culture}

CD34 $4^{+}$cells were cultured for 5-11 days in StemPro-34 medium supplemented with 10\% ES-FBS, SCF, FLT3L, TPO and IL-3.. The medium was refreshed every 3 days. Cells were analyzed for GFP and immature populations (Online Supplementary Table S2).

\section{Quantitative reverse transcription polymerase chain reaction}

RNA was isolated by a Quick RNA Micro Prep kit (Zymo Research) and reversely transcribed to cDNA (QuantitecReverse transcription kit, OIAgen). Quantitative reverse transcription polymerase chain reaction (qRT-PCR) was performed by using BIO-RAD (CFX96 Touch) a RT-PCR detection system and SYBR Green master mix (Thermofisher). Expression of the gene of interest was normalized to the expression of either $18 \mathrm{~S}$ or $36 B 4$.

\section{Reverse transcriptase multiplex ligation dependent probe amplification}

RNA samples from $\mathrm{CD} 34^{+}$cells cultured under different conditions were obtained by a Quick RNA Micro Prep kit (Zymo Research). Reverse transcriptase multiplex ligation dependent probe amplification (RT-MLPA) was performed according to the manufacturer's instructions (MRC Holland, R011-C1). The resultant amplicons were separated by capillary electrophoresis (ABI-3130xl Genetic Analyzer) and Sequence Pilot (JSI Medical Systems) was used for the analysis. The sum of all peaks was taken as $100 \%$, and the values of the single peaks were normalized accordingly.

\section{Xenotransplantation}

All experiments were performed after approval from the local ethics committee and in compliance with German law. $\operatorname{Rag}^{--} \gamma \mathrm{C}^{-/-}$mice were kept under specific pathogen-free conditions. Newborn mice were sub-lethally irradiated with $2.5 \mathrm{~Gy}{ }^{30}$ After $6 \mathrm{~h}$, the progeny of $1 \times 10^{5}$ transduced or untransduced human $\mathrm{CD}_{3} 4^{+}$cells were injected intrahepatically. Mice were sacrificed for analysis after 8 weeks.

\section{Flow cytometry}

Single cell suspensions obtained from colony-forming assays or hematopoietic organs from mice were surface stained with monoclonal antibodies: CD34 PE-Cy7(581), CD38 APC (HIT2), CD10 PE/APC (HI10a), CD45RA PerCP-Cy5.5 (HI100), CD90 APC-Cy7 (5E10), CD117 PE-Cy7 (104D2), CD71 APC (CY1G4), CD33 PE (WM53), CD14 APC (M5E2), CD115 BV421 (4D21E4), CD15 PeCy5 (W6D3), CD66b PerCP-Cy5.5 (G10F5), CD19 PE-Cy7 (HIB19), IgM APC-Cy7 (MHM-88), CD45 Biotin (HI30), CD45 PE-Cy7/V500 (30-F11) (Biolegend), and CD235a BV421 (HIR2) (BD Biosciences). Streptavidin PerCP-Cy5.5/V450 (Biolegend) was used as a secondary antibody. BD LSRFortessa and FlowJo were used for flow cytometry and analyses, respectively. The gating strategy was published earlier. ${ }^{31}$

\section{Western blot}

Purified proteins were size fractioned by $12 \%$ sodium dodecylsulfate polyacrylamide gel electrophoresis under reducing conditions and transferred onto polyvinylidene difluoride membranes. The antibodies used were: MCL-1 (D2W9E) rabbit monoclonal antibody, BCL-XL (54H6), BCL-2 (D17C4), BFL1/A1 (D1A1C), $\alpha / \beta$-tubulin or $\beta$-actin (13E5) (all rabbit, Cell Signaling). A peroxidase-coupled goat anti-rabbit IgG secondary antibody was used (sc-2004, Santa Cruz).

\section{Statistics}

Statistical analyses were performed using the unpaired MannWhitney test in GraphPad Prism 7 software. $P$ values less than 0.05 were considered statistically significant. Synergy of BCL-XL and MCL-1 inhibitors was calculated using the Bliss synergy score and the program SynergyFinder (https://synergyfinder.fimm. $f$ ) ${ }^{32}$

\section{Results}

\section{MCL-1 knockdown sensitizes human CD34+ cells selectively to endoplasmic reticulum stress}

Putative shRNA sequences specific for MCL-1 were tested in transfected HEK293T cells. For shRNA delivery into human $\mathrm{CD} 34^{+}$cells, a lentiviral system that allowed stable expression of the shRNA and GFP was used. Two different shRNA sequences, both binding to exon 3 of the human $M C L-1$ gene, were identified to reduce $M C L$ 1 mRNA expression to $25-55 \%$ in HEK293T and by $41-$ $55 \%$ in human cord blood-derived CD34 ${ }^{+} \mathrm{HSPC}$ (Figure 1A). Knockdown of the Luciferase (Luci) gene was used as a negative control. Efficient MCL-1 knockdown was confirmed on a protein level in HEK293T and CD34 ${ }^{+}$ cells and showed, at least in $\mathrm{CD}_{34}{ }^{+}$cells, no relevant differences between the two shRNA sequences used (Figure $1 B, C)$. Transduction efficiency was similar for the different viruses (Online Supplementary Figure S1B) but CD34 cells transduced with shRNA specific for MCL-1 showed increased apoptosis rates $24 \mathrm{~h}$ after transduction (Figure 1D). The surviving cells were cultured and treated for 24 $\mathrm{h}$ and $48 \mathrm{~h}$ with different cytotoxic drugs including the DNA damaging agent etoposide, the mitotic spindle inhibitor taxol and different compounds inducing endoplasmic reticulum (ER) stress (i.e., tunicamycin, thapsigargin and brefeldin A) (Figure 1E, F). Interestingly, MCL1 inhibition selectively increased the sensitivity of CD34+ cells to ER stress (Figure 1E, F). While transduced $\mathrm{GFP}^{+}$ cells expressing MCL-1 shRNA were killed in a dosedependent manner (Online Supplementary Figure S2A), $\mathrm{GFP}^{+}$cells expressing Luci shRNA or non-transduced GFP cells did not undergo increased cell death upon ER stress (Online Supplementary Figure S2A, B). These findings indicate that MCL-1 inhibition increased cellular sensitivity in a stress-dependent and cell-intrinsic manner. Since knockdown of MCL-1 was not complete in $\mathrm{CD}^{+} 4^{+}$cells, we hypothesized that ER stress itself reduced MCL-1 levels, thereby leading to critical depletion of this protein once combined with the gene knockdown. Indeed, we found significant and dose-dependent

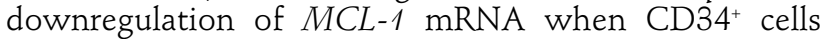
were treated with tunicamycin (Figure 1G). At the same time, tunicamycin led to downregulation of $B C L-X L$ mRNA and upregulation of the BH3-only proteins $P U M A$ and BMF (Online Supplementary Figure S2C). Upregulation of CHOP and PERK mRNA confirmed the presence of ER stress (Online Supplementary Figure S2D). In summary, ER stress shifts the BCL-2 equilibrium towards apoptosis, which is initiated once levels of 
A

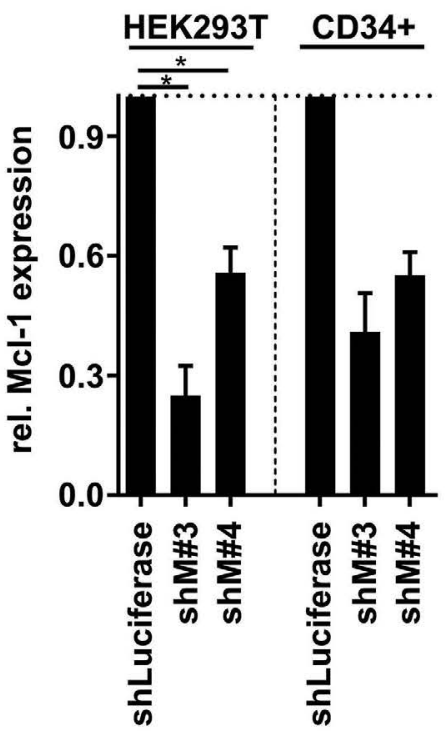

D

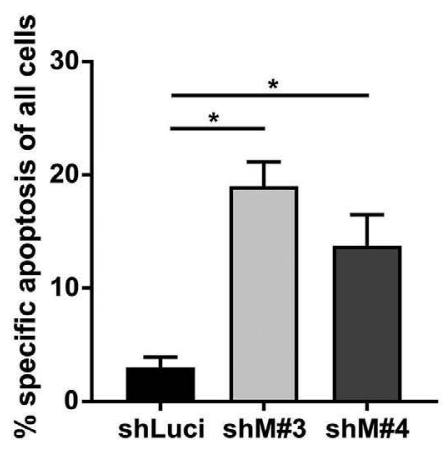

$\mathrm{F}$

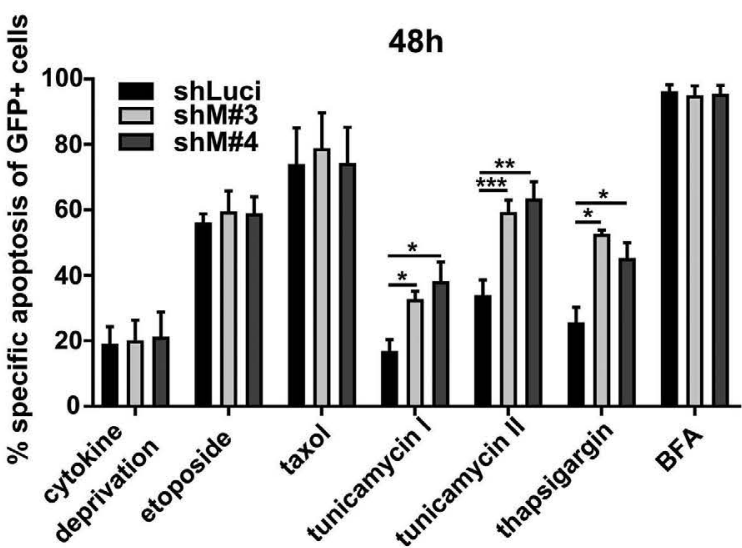

kDa shLuci shM\#3 shM\#4

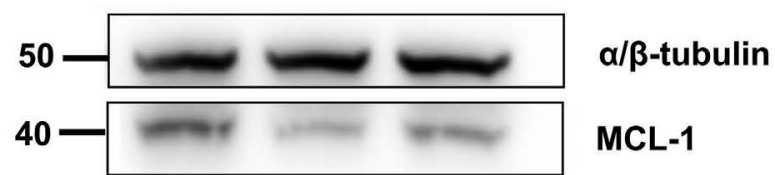

C

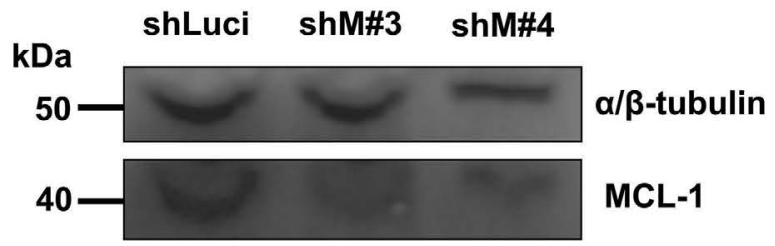

E

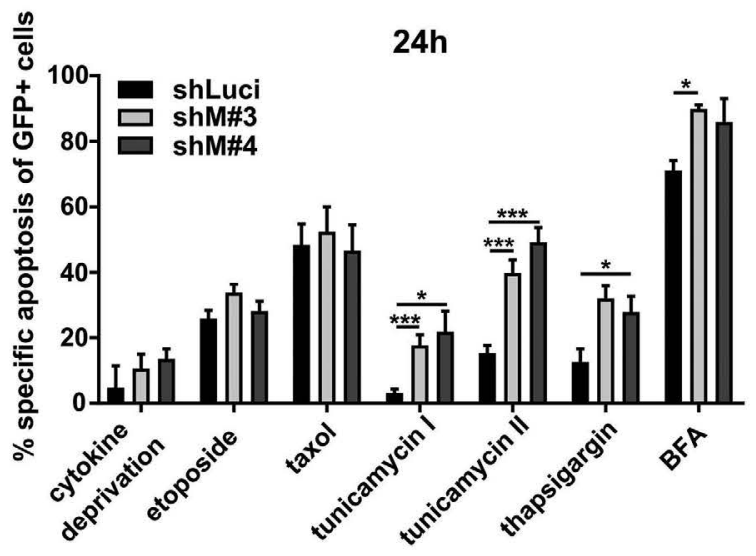

G

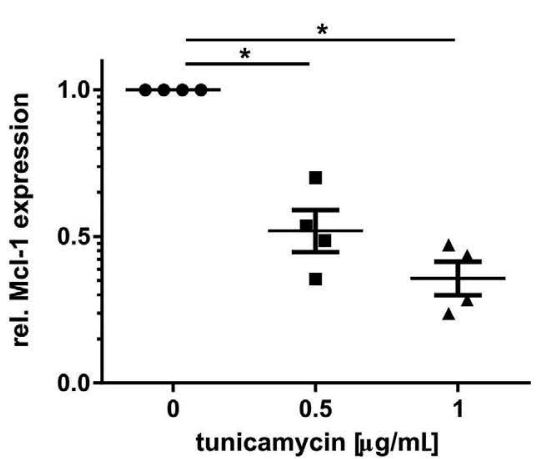

Figure 1. MCL-1 inhibition selectively sensitizes human CD34+ cells to endoplasmic reticulum stress. (A) HEK293T cells were transfected with plasmids expressing shRNA specific for Luciferase (shLuci) or human MCL-1 (shM\#3 or shM\#4). MCL-1 mRNA expression was determined in sorted GFP+ cells and normalized to the $36 B 4$ reference gene. Bars represent mean \pm standard error of mean (SEM); $n=5$ from five independent experiments. Human cord blood-derived CD34 ${ }^{+}$cells were transduced with the corresponding lentiviruses. $\mathrm{GFP}^{+}$cells were sorted $24 \mathrm{~h}$ after transduction, and knockdown efficiency of $\mathrm{MCL}$ - 1 was determined by quantitative reverse transcription polymerase chain reaction (qRT-PCR). mRNA expression was normalized to $18 \mathrm{~S}$ expression. Bars represent mean $\pm \mathrm{SEM}$; $\mathrm{n}=2-4$ from four independent experiments. Mann-Whitney test: $* P<0.05$. (B, C) MCL-1 protein levels were determined in HEK293T (B) and CD34 ${ }^{+}(C) \mathrm{GFP}^{+}$cells. (D) Measurements of apoptosis in $\mathrm{CD}^{+}{ }^{+}$cells $24 \mathrm{~h}$ after lentiviral transduction revealed that $14-19 \%$ of cells undergo apoptosis early after MCL- 1 depletion. Bars represent mean $\pm \mathrm{SEM}$; $\mathrm{n}=4$ from four independent experiments. (E, F) Transduced CD34+ cells (transduction efficiency $45-65 \%$ ) were cultured either under optimal conditions (cytokines and $10 \%$ serum) or under conditions of stress; in the presence of serum but deprived of cytokines, etoposide $(0.5 \mu \mathrm{g} / \mathrm{mL})$, taxol $(0.125 \mu \mathrm{g} / \mathrm{mL})$, tunicamycin I and II $(0.5 \mathrm{and}$ $1 \mu \mathrm{g} / \mathrm{mL}$, respectively), thapsigargin $(3 \mu \mathrm{M})$ or brefeldin A (BFA; $0.5 \mu \mathrm{g} / \mathrm{mL})$. Apoptosis in GFP+ cells was determined by flow cytometry using annexin $\mathrm{V}$ and $7-\mathrm{AAD}$ staining $24 \mathrm{~h}(\mathrm{E})$ and $48 \mathrm{~h}(\mathrm{~F})$ later. Bars represent mean $\pm \mathrm{SEM} ; \mathrm{n}=3-8$ from eight independent experiments. Mann-Whitney test: $* P<0.05, * * P<0.01, * * * P<0.001$. (G) RNA was isolated from CD34 cells treated with increasing concentrations of tunicamycin and used for qRT-PCR. MCL-1 mRNA expression was normalized to $18 \mathrm{~S}$ expression. Bars represent mean $\pm \mathrm{SEM} ; \mathrm{n}=4$ from four independent experiments. Mann-Whitney test: $* P<0.05$. 
either MCL-1 (shown here) or BCL-XL (documented earlier $)^{31}$ are further reduced by RNA interference.

Human hematopoietic stem and progenitor cells show impaired colony formation and differentiation upon MCL-1 knockdown

To test the effect of MCL-1 knockdown on colony formation and differentiation of human CD34+ cells, we cultured 1,000 transduced and sorted $\mathrm{GFP}^{+}$cells for 11 days in MethoCult medium containing the cytokines SCF, IL3, IL-6, erythropoietin (EPO), granulocyte colony-stimulating factor (G-CSF), granulocyte-macrophage colonystimulating factor (GM-CSF), insulin and transferrin. The number of colonies arising was significantly lower when MCL-1 expression was inhibited (Figure 2A). All colony types were affected, indicating that all multipotent and lineage-committed progenitor cell types were lost to a similar degree (Figure 2B). In addition, fewer cells could be harvested from plates (Figure 2C). Flow cytometry revealed that all cell types were reduced in number when MCL-1 was depleted (Online Supplementary Figure S3A). Since we noticed a relevant toxicity of the sorting procedure on lentivirally-transduced cells, we repeated the experiment using unsorted cells. With this approach, we could directly compare transduced $\mathrm{GFP}^{+}$with untransduced GFP cells. Colony numbers and types were similar

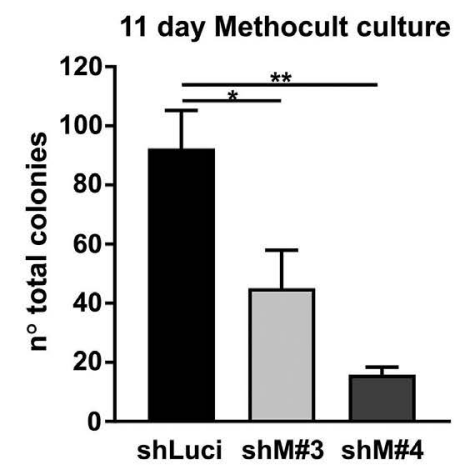

D

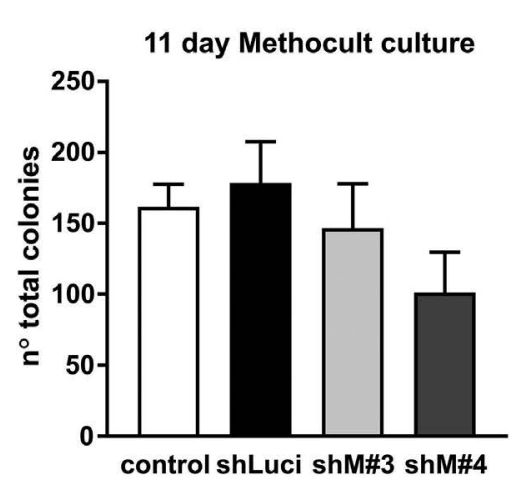

\section{colony formation from sorted CD34+ cells}

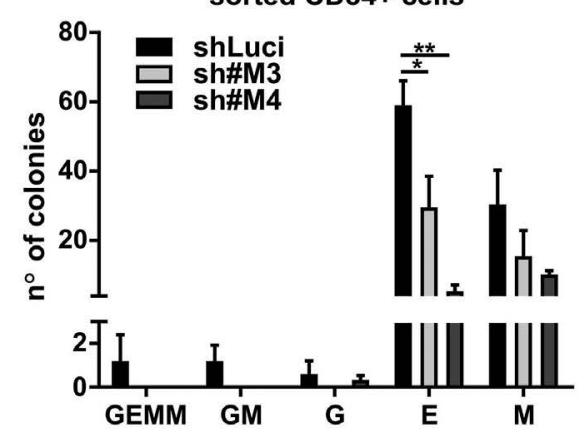

E

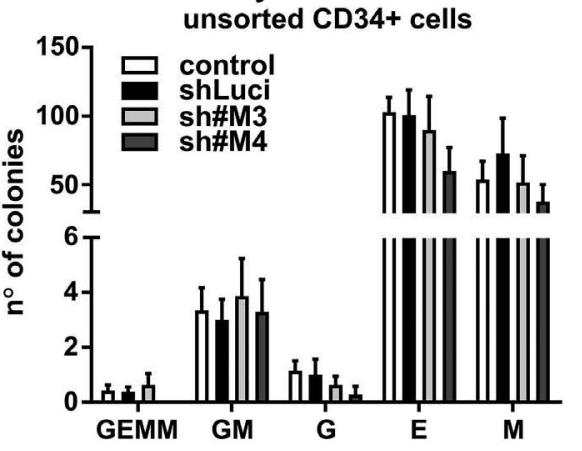

C

11 day Methocult culture

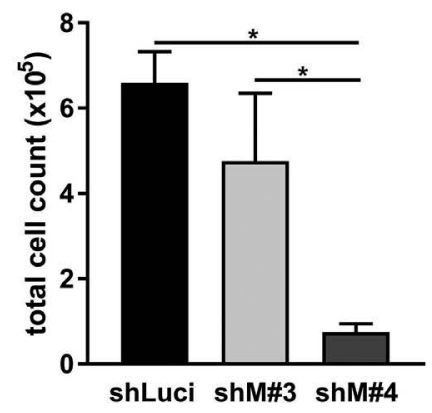

$\mathbf{F}$

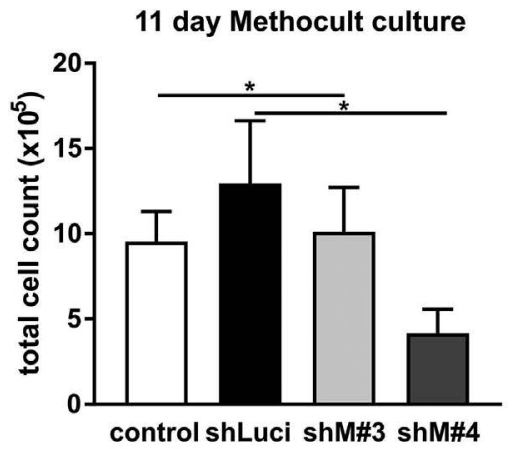

G

11 day Methocult culture of unsorted CD34+ cells

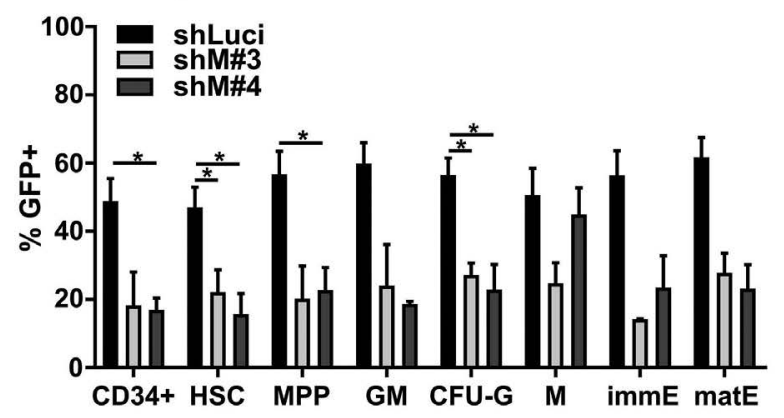

Figure 2. MCL-1 is essential for all hematopoietic progenitor cells. (A-C) Lentivirally transduced human CD34 ${ }^{+}$cells were sorted for GFP expression. GFP+CD34+ cells were seeded in MethoCult medium (1,000 cells each). (D-G) Alternatively, unsorted cells were plated. (A, D) After 11 days of culture, colonies were counted by light microscopy. (B, E) Based on morphological findings, the following colony types were identified by light microscopy: GEMM: granulocytic-erythroid-megakaryocyticmonocytic, GM: granulocytic-monocytic, G: granulocytic, E: erythroid, M: monocytic. (C, F) Cells were dissolved from the semisolid medium and counted by a hemocytometer. (G) The different hematopoietic cell types were determined by flow cytometry. The percentages of GFP ${ }^{+}$cells are shown within each of the following cell populations: HSC; hematopoietic stem cells (CD34+CD38CD45RACD90+), MPP: multipotent progenitors (CD34+38-CD45RACD90), GM: granulocytic-monocytic progenitors (CD34 $\left.{ }^{+} \mathrm{CD} 33^{+} \mathrm{CD} 115^{+}\right)$, CFU-G: colony forming unit-granulocytes (CD34 CD33 $\left.{ }^{+} \mathrm{CD} 15^{+} \mathrm{CD} 115\right)$, M: monocytes $\left(\mathrm{CD} 34 \mathrm{CD}^{\circ} 3^{+} \mathrm{CD} 14^{+} \mathrm{CD} 115\right)$, immE: immature erythrocytes $\left(C D 71^{\text {hi }} C D 235 a\right)$, matE: mature erythrocytes $\left(C D 71^{+} C D 235 a^{+}\right)$. Bars represent mean \pm standard error of mean, $n=6(A-C)$ from six independent experiments and $n=4$ (D-G) from four independent experiments. Mann-Whitney test: $* P<0.05, * * P<0.01$. 
in all groups (Figure 2E, F) and cell numbers were not consistently reduced when MCL-1 was downregulated (Figure 2G). However, while transduction rates were comparable (Online Supplementary Figure S3B), MCL-1depleted $\mathrm{GFP}^{+}$cells were selectively lost during the 11 days of MethoCult culture, indicating their selective disadvantage (Figure 2H, Online Supplementary Figure S3B). Loss of MCL-1 affected all analyzed immature and mature cell types in a similar manner, confirming that all progenitor cell types were dependent on MCL-1 expression (Figure 2H, Online Supplementary Figure S3C). To analyze whether MCL-1-depleted cells were lost immediately or progressively over time, we cultured them for only 5 days in MethoCult medium. At this early time point, only mild loss of $\mathrm{GFP}^{+}$cells was observed, independently of the lentivirus used (Figure 3A, left). This indicates that progenitor cells became more susceptible to MCL-1 inhibition once they progressed in their differentiation process. Accordingly, immature $\mathrm{CD}_{3} 4^{+}$cells and specifically hematopoietic stem cells and multipotent progenitors were enriched in the first days of culture (Figure 3B, Online Supplementary Figure $S 3 D, E$ ). To inhibit differentiation but foster proliferation, $\mathrm{CD} 34^{+}$cells were cultured in the presence of the cytokines SCF $(200 \mathrm{ng} / \mathrm{mL})$, FLT3L (200 $\mathrm{ng} / \mathrm{mL})$, TPO (100 $\mathrm{ng} / \mathrm{mL})$ and IL-3 (20 ng/mL). CD34 and GFP expression was measured after 5 and 11 days. Under this condition, the percentage of $\mathrm{CD} 34^{+}$cells remained high (Figure $3 \mathrm{~B}$, right) and $\mathrm{GFP}^{+}$cells were not depleted in a relevant manner (Figure $3 \mathrm{~A}$, right). To exclude that expression of shRNA and, consequently, MCL-1 knockdown was different in the two culture conditions, we measured MCL-1 mRNA after 5 days of culture. While we observed stable MCL-1 knockdown by shRNA \#3, the shRNA \#4 showed less consistent results

A

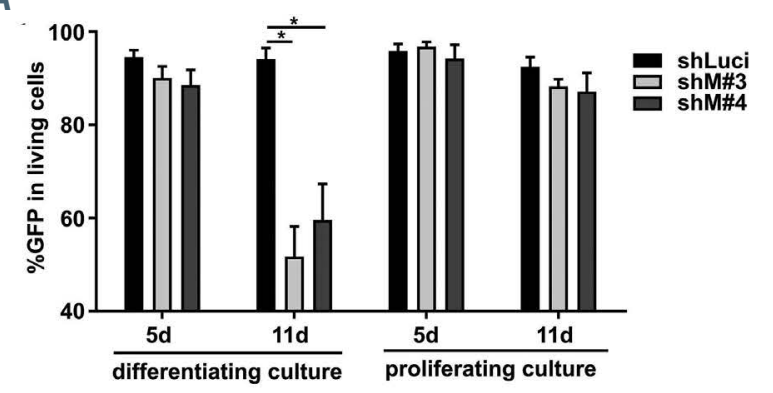

C

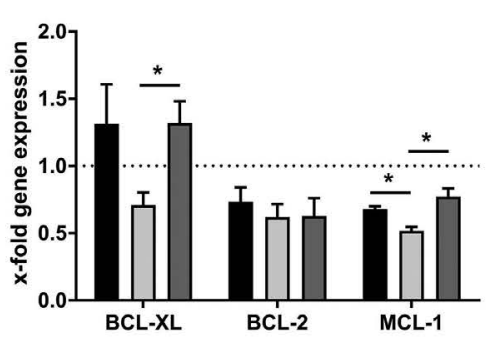

D with re-expression of $M C L-1$ mRNA (Online Supplementary Figure S3F). However, no difference in knockdown efficiency was observed between the two culture conditions indicating that the dependence of HSPC on MCL-1 did indeed change during proliferation and differentiation, respectively.

To understand why MCL-1 dependence was so different under the two culture conditions, we determined the composition of all BCL-2 proteins by RT-MLPA. As controls, we used freshly isolated $\mathrm{CD} 34^{+}$cells. Interestingly, both MCL-1 and BCL-XL were expressed at higher levels in cells stimulated to differentiate for 4 days (Figure 3C). Among the pro-apoptotic BCL-2 proteins, PUMA was highly upregulated under both culture conditions (i.e., differentiation and proliferation conditions) while BIM, BID and BAK1 were selectively upregulated under differentiation conditions (Figure 3D, E). Thus, it is possible that differentiation is associated with stronger pro-apoptotic signals that need to be counteracted by higher MCL-1 and BCL$\mathrm{XL}$ levels. Based on its binding affinities, it is conceivable that MCL-1 expression is required to counteract BIMmediated activation of BAK1.

MCL-1 inhibition severely restricts hematopoietic stem and progenitor cell engraftment in xenografted mice

In order to determine the effects of MCL-1 inhibition on the engraftment potential of human CD34+ HSPC, untransduced and transduced cells were intrahepatically transplanted into sublethally irradiated $\operatorname{Rag} 2^{-1} \gamma c^{-/}$mice. To reduce cell stress prior to transplantation, we waived the sorting procedure and transplanted $\mathrm{GFP}^{+}$cells together with GFP cells. After 8 weeks, xenografted mice were sacrificed and human engraftment was analyzed. Lentivirally transduced cells had a reduced potential to engraft but

B
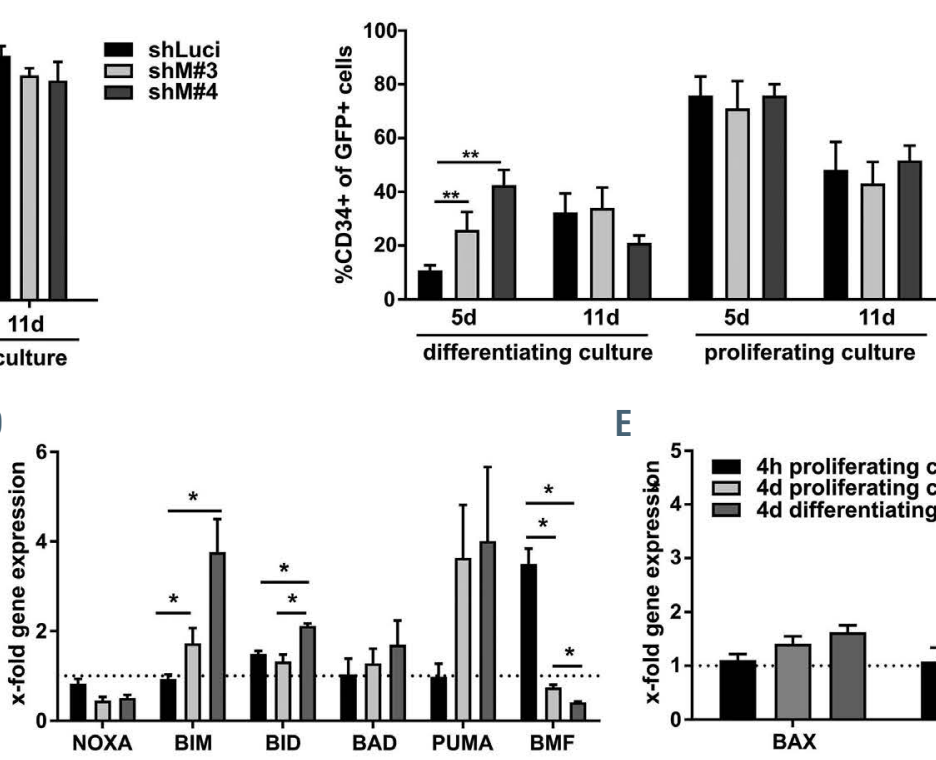

E

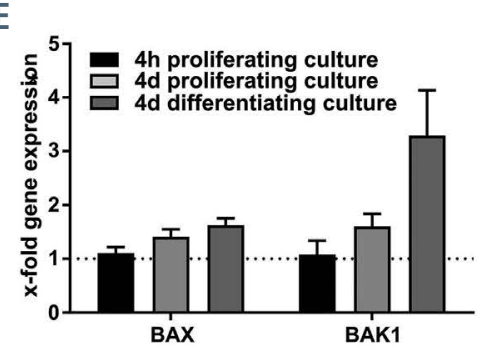

Figure 3. MCL-1 expression is more important for differentiating than for proliferating CD $34^{+}$cells. (A) Sorted CD34+GFP+ cells were subjected to either differentiating or proliferating culture conditions. To induce differentiation, cells were cultured in semisolid MethoCult plates for 5 days (3,000 cells seeded per plate) or 11 days ( 1,000 cells seeded per plate). To foster proliferation, cells were cultured in stem cell medium containing $10 \%$ serum and stem cell factor, FLT3L ( $200 \mathrm{ng} / \mathrm{mL}$ each), thrombopoietin $(100 \mathrm{ng} / \mathrm{mL})$ and interleukin-3 $(20 \mathrm{ng} / \mathrm{mL})$. After 5 and 10 days of culture, the percentages of GFP ${ }^{+}$cells were determined by flow cytometry. (B) The fraction of $\mathrm{CD}_{3} 4^{+}$cells was determined within $\mathrm{GFP}^{+}$cells at each time point. (C-E) Untransduced $\mathrm{CD} 34^{+}$cells were subjected to the two different culture conditions and harvested at the indicated time points. mRNA was used for reverse transcriptase-multiplex ligation dependent probe amplification designed to determine levels of apoptosis genes. Results are shown for anti-apoptotic BCL-2 proteins (C), BH3-only proteins (D) and pro-apoptotic effector proteins (E). Freshly isolated CD34 ${ }^{+}$cells were used as controls. Bars represent mean \pm standard error of mean, $\mathrm{n}=4$ from four independent experiments. Mann-Whitney test: $* P<0.05, * \star P<0.01$. 
there were no differences between the viruses used (Figure 4A). As known from this model system, most cells differentiated into $\mathrm{CD}^{2} 9^{+} \mathrm{B}$ cells while fewer $\mathrm{CD} 33^{+}$myeloid cells and almost no $\mathrm{CD}^{+} \mathrm{T}$ cells arose (Figure $\mathrm{AB}$ and data not shown). Cells expressing the control shRNA (Luci) engrafted and contributed to all lineages (Figure 4C, D). In contrast, cells expressing shRNA specific for MCL-1 showed only very poor engraftment (Figure 4C). In line with the important role of MCL-1 for survival of immature progenitors with multipotent potential, all cell types found in the xenografted mice were equally affected (Figure 4D).

\section{MCL-1 inhibition limits the survival of immature but not mature hematopoietic cells}

To determine the effects of MCL-1 inhibition on more mature types of hematologic cells, we used the specific MCL-1 inhibitor S63845. First, we treated freshly isolated immature $\mathrm{CD}_{4} 4^{+}$and mature CD34 cells with increasing doses of the inhibitor. While $\mathrm{CD} 34^{+}$cells were moderately sensitive when compared to cancer cell lines (e.g., IC $\mathrm{I}_{\text {in }}$ in most multiple myeloma cell lines $<0.1 \mu \mathrm{M}$ ) ${ }^{28}$ no apoptosis was induced after $24 \mathrm{~h}$ and $48 \mathrm{~h}$ in mature CD34 blood cells even when very high doses of inhibitor were used (Figure 5A, B).

In a second approach, we let untreated $\mathrm{CD} 34^{+}$cells differentiate for 11 days in MethoCult medium. Cells were then isolated and put into stem cell medium containing $10 \%$ ES-FBS and cytokines (SCF, TPO, FLT3L, IL-3). Different concentrations of the MCL-1 inhibitor were added, and cell numbers were determined after $24 \mathrm{~h}$. Again, differentiated CD34 cells were much less sensitive than immature $\mathrm{CD} 34^{+}$cells (Figure 5C, D). As a consequence, only a mild and non-significant reduction in cell numbers was noted (Figure 5C) and both myeloid and erythroid cells were depleted only to a minor and non-significant degree (Figure 5D).

Stem and progenitor cells from neonates and adults are equally sensitive to MCL-1 or BCL-XL inhibition

Our experiments indicate a strong dependence of human HSPC on MCL-1 expression, which is not unexpected considering the high relevance of MCL-1 for survival of murine HSPC. ${ }^{25,26}$ However, other authors described an overall good tolerability of human HSPC to MCL-1 inhibitors. ${ }^{33-35}$ One reason for this discrepancy could be that we used $\mathrm{CD} 34^{+}$cells derived from cord blood while CD34 cells derived from the bone marrow of aged persons were used in other studies. ${ }^{33}$ We therefore compared these two cell types with regards to protein levels of MCL-1 and other anti-apoptotic BCL-2 family members. Bone marrow $\mathrm{CD} 34^{+}$cells were obtained from patients with orthopedic problems (age range: 44 to 90 years). While MCL-1 and
A

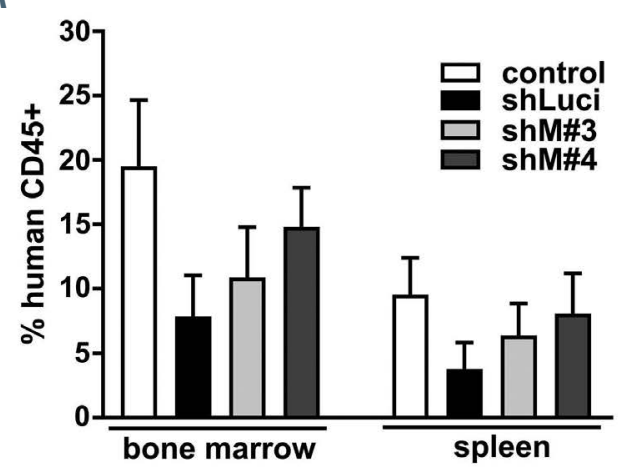

C

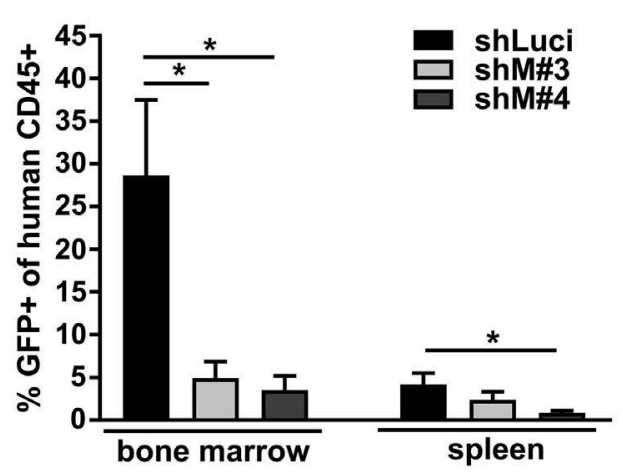

B

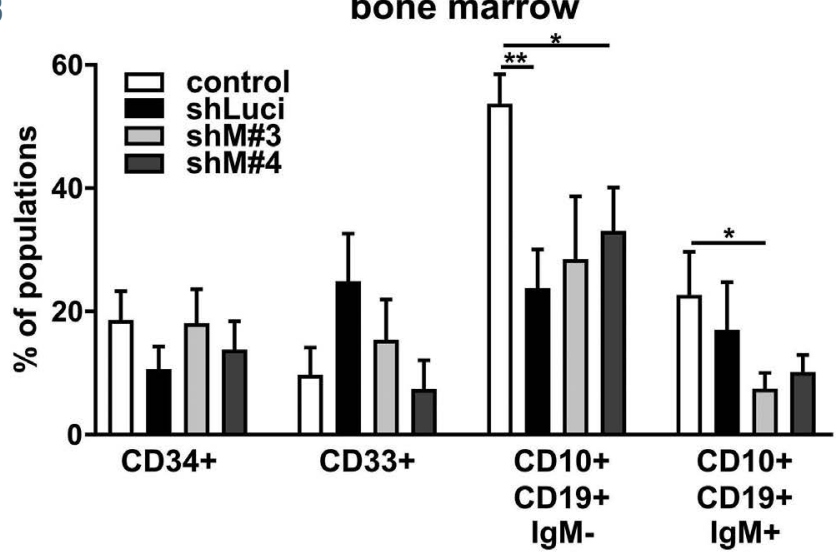

D

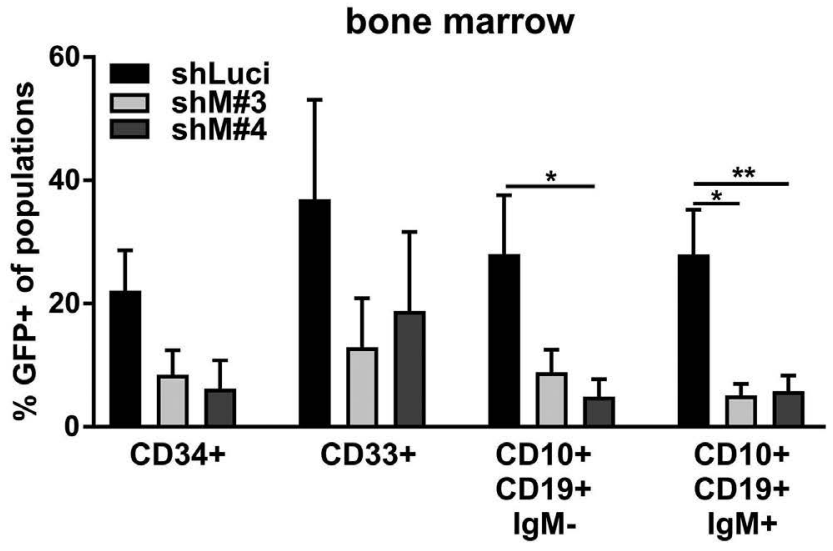

Figure 4. Human $\mathrm{CD} 34^{+}$cells lacking MCL-1 show poor engraftment in xenografted mice. (A-D) Lentivirally transduced or untransduced human hematopoietic stem and progenitor cells (HSPC) were transplanted intrahepatically into newborn Rag2 $2^{-1-} \gamma c^{-/-}$mice after sub-lethal irradiation. Mice were sacrificed 8 weeks after transplantation and bone marrow (BM) and spleen populations were analyzed. By using antibodies specific for human or murine CD45, percentage human engraftment was determined (A). The various human hematopoietic populations were determined within the huCD45 ${ }^{+}$cells using flow cytometry (B). GFP expression was determined in huCD $45^{+}$cells $(C)$ and in each of the subpopulations (D). Bars represent mean \pm standard error of mean, $n=9-13$ from eight independent experiments. Mann-Whitney test was performed; $* P<0.05, * * P<0.01$. 
BCL-XL levels were identical in both cell types and A1 was not expressed, BCL-2 levels were higher in adult HSPC than in HSPC from neonates (Figure 6A).

Next, we performed comparative functional studies using the MCL-1 inhibitor S63845, the BCL-XL inhibitor A-1155463 and the BCL-2 inhibitor ABT-199. By treating bone marrow immature $\mathrm{CD}_{3} 4^{+}$and differentiated CD34cells with the MCL-1 inhibitor for $24 \mathrm{~h}$ and $48 \mathrm{~h}$, we obtained similar results as those with cord blood cells (compare Figure 6B with Figure 5A, B). Chemical inhibition of MCL-1 also confirmed our RNA interference experiments: when we added the inhibitor S63845 to cord blood $\mathrm{CD} 4^{+}$cells cultured in MethoCult medium, colony formation was impeded in a dose-dependent manner (compare Figure $6 \mathrm{C}$ with Figure 2). The numbers of immature cell types, including hematopoietic stem cells, multipotent progenitors and mixed lymphoid progenitors, were significantly reduced (Figure 6C, right panel). Similarly, all emerging erythroid and myeloid cells (Figure 6C, right panel) were depleted in a dose-dependent manner. Importantly, there was no difference in MCL-1 inhibitor sensitivity in $\mathrm{CD}^{+} 4^{+}$cells derived from cord blood (Figure $6 \mathrm{C}$ ) or bone marrow (Figure 6D).

We have shown earlier that BCL-XL, too, is important for keeping human cord blood CD34 $4^{+}$cells alive, ${ }^{31}$ a finding that was unexpected considering its dispensable role for mouse HSPC. ${ }^{36.38}$ We now extended our studies to bone marrow-derived cells and showed that $\mathrm{CD} 34^{+}$cells were more sensitive than CD34 cells to the BCL-XL inhibitor A1155463 (Figure 7A). We compared colony-forming potential CD34+ cells derived from cord blood or bone marrow and observed no difference between the two cell types: BCL-XL inhibition resulted in significant reduction of colony formation (Figure 7B) and cell numbers (Figure 7C), independently of the source of the human HSPC. Notably, effects on colony formation were less pronounced than those caused by MCL-1 inhibition. As documented earlier, immature CD34 $4^{+}$cells (Figure 7D) as well as mature erythroid cells (Figure 7E) were more severely affected than myeloid cells (Figure 7F).

Finally, the BCL-2 inhibitor ABT-199 did not negatively affect survival or colony formation of cord blood- or bone marrow-derived $\mathrm{CD} 34^{+}$cells, even when used at the high concentration of $1 \mu \mathrm{M}$ (Online Supplementary Figure S4). This finding is consistent with the relatively mild myelosuppressive effects of venetoclax observed in clinical trials. $^{39}$

\section{Synthetic lethality of MCL-1 and BCL-XL inhibitors} in human hematopoietic stem and progenitor cells

We noted a striking functional homology of MCL-1 and BCL-XL for survival of human HSPC and concluded that combined inhibition of both anti-apoptotic proteins could result in complete depletion of colony-forming stem and progenitor cells. To test this, we treated cord blood-derived $\mathrm{CD} 34^{+}$cells with increasing doses of the
A
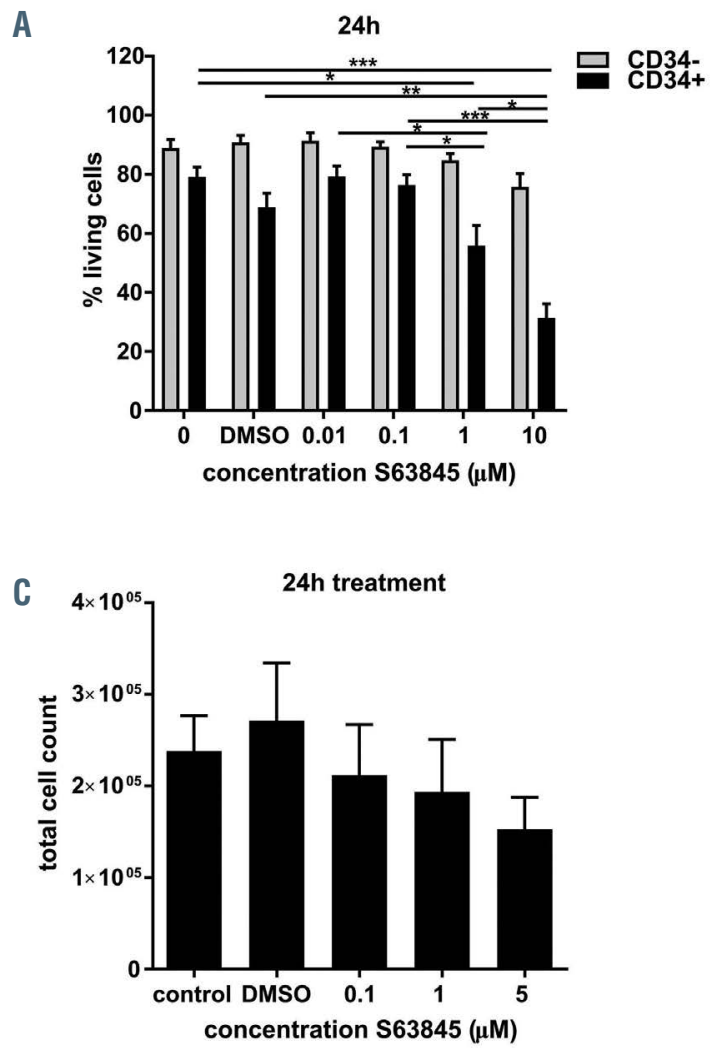

B

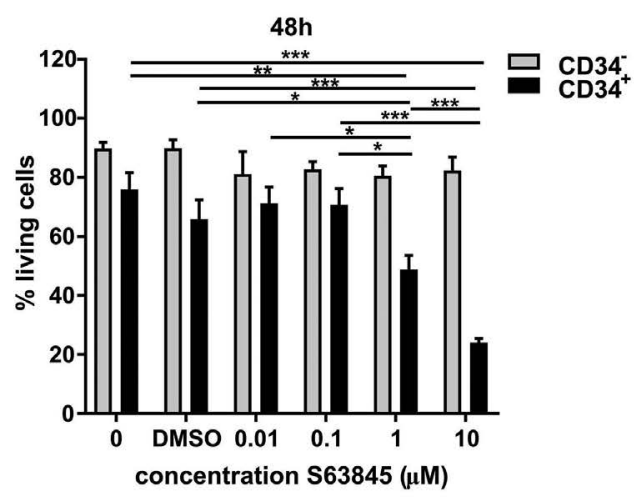

D

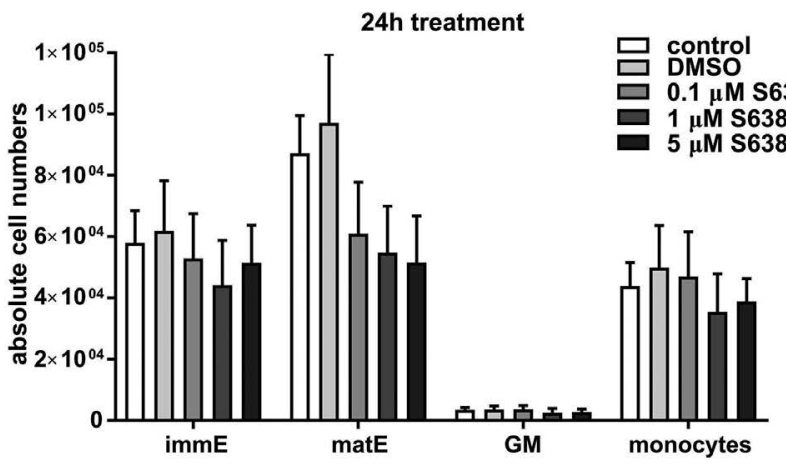

Figure 5. Survival of mature hematopoietic cells is independent of MCL-1. (A-B) Freshly isolated cord blood was subjected to density gradient centrifugation and mononuclear cells were divided into $\mathrm{CD} 34^{+}$and $\mathrm{CD} 34$ cells using magnetic activated cell sorting technology. Both cell fractions were treated with the indicated concentrations of the MCL-1 inhibitor S63845. After $24 \mathrm{~h}(\mathrm{~A})$ and $48 \mathrm{~h}(\mathrm{~B})$, percentages of living cells were determined by flow cytometry using annexin V/7-AAD. Bars represent mean \pm standard error mean (SEM); $n=3-6$ from six independent experiments. (C-D) CD34 ${ }^{+}$cells were differentiated in MethoCult culture. After 11 days, differentiated cells were isolated and treated with $\mathrm{S} 63845$ for $24 \mathrm{~h}$. Total cell numbers (C) were determined and erythroid and myeloid cell populations (D) were analyzed by flow cytometry ( $\mathrm{n}=5$ from 5 independent experiments). Bars represent mean \pm SEM. Mann-Whitney test: $* P<0.05, * * P<0.01, * * * P<0.001$. 
A

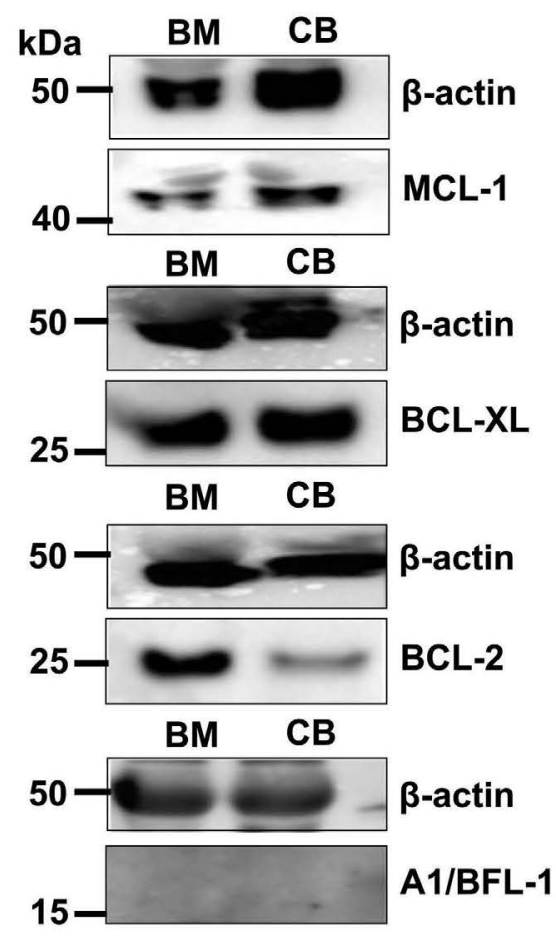

B
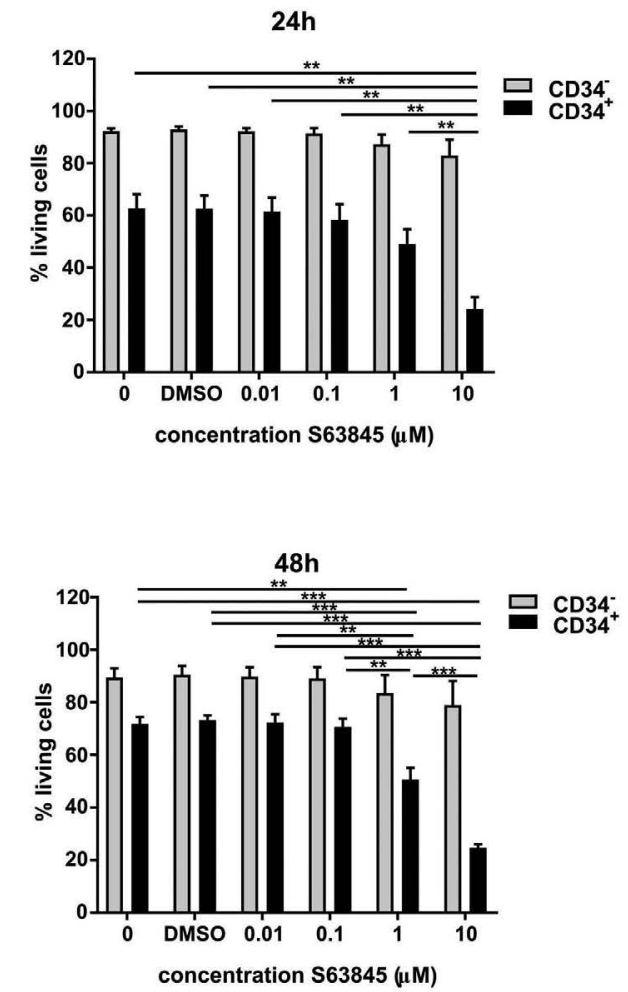

C

cord blood CD34+
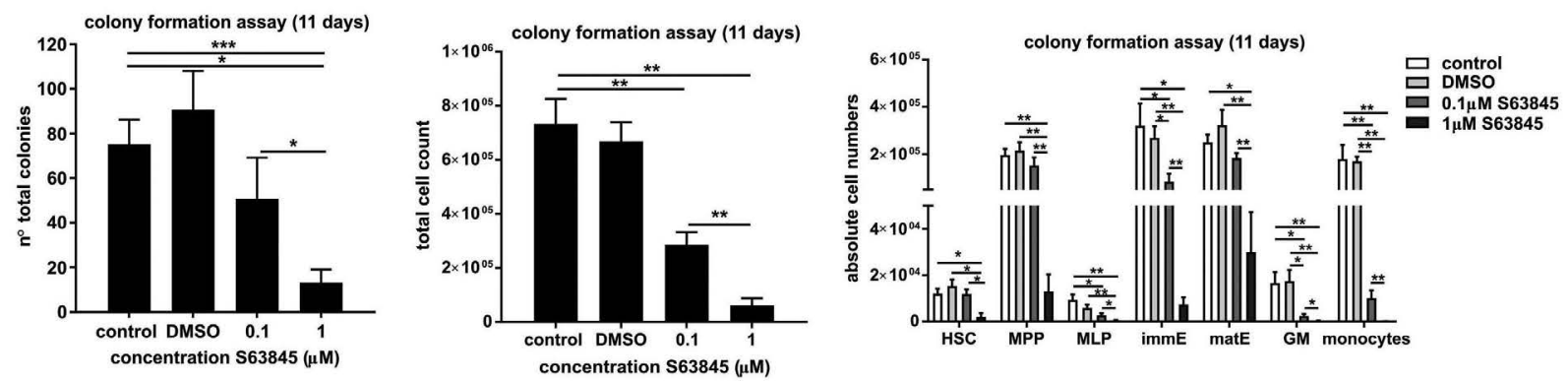

D

bone marrow CD34+
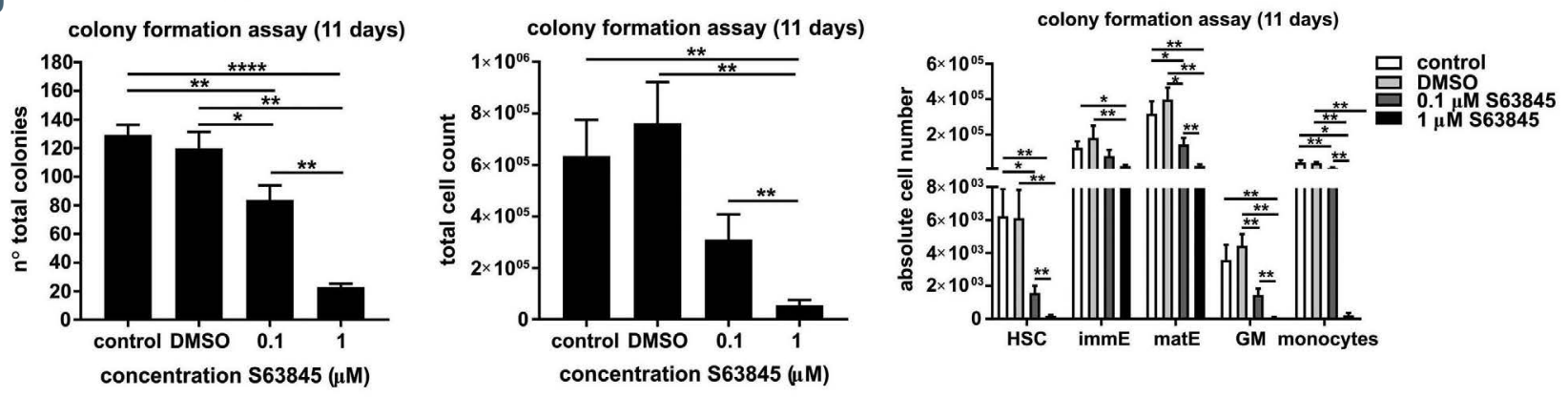

Figure 6. MCL-1 is essential for survival of both cord blood- and bone marrow-derived human $\mathrm{CD} 34^{+}$cells. (A) Protein levels of the anti-apoptotic BCL-2 family members MCL-1, BCL-XL, BCL-2 and BFL1/A1 were determined in CD34+ cells isolated from both cord blood and bone marrow. $\beta$-actin served as a loading control. (B) Freshly isolated bone marrow was subjected to density gradient centrifugation and mononuclear cells were divided into CD34 ${ }^{+}$and $\mathrm{CD} 34$ cells using magnetic activated cell sorting technology. Both cell fractions were treated with the indicated concentrations of the MCL-1 inhibitor S63845. After $24 \mathrm{~h}$ (upper panel) and $48 \mathrm{~h}$ (lower panel), percentages of living cells were determined by flow cytometry using annexin V/7-AAD. Bars represent mean \pm standard error of mean (SEM); $\mathrm{n}=6-7$ from seven independent experiments. (C-D) Human CD34+ cells isolated from either cord blood (C) or bone marrow (D) were differentiated in MethoCult medium containing 0.1 or 1 uM S63845. As controls, untreated and dimethylsulfoxide (DMSO)-treated cells were used ( $n=7$ from seven independent experiments). After 11 days, total colony numbers (left) and total cell numbers (middle) were determined using light microscopy and hemocytometry, respectively. Different immature and differentiated cell types were determined by flow cytometry, and their absolute cell numbers were calculated (right). The following cell types were studied; HSC:

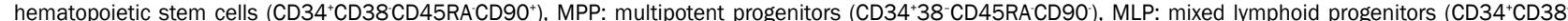
CD45RA $\left.{ }^{+} \mathrm{CD} 10^{+}\right) \mathrm{GM}$ : granulocytic-monocytic progenitors $\left(\mathrm{CD} 34^{+} \mathrm{CD} 33^{+} \mathrm{CD} 115^{+}\right)$, M: monocytes $\left(\mathrm{CD} 34 \mathrm{CD}^{2} 3^{+} \mathrm{CD} 14^{+} \mathrm{CD} 115\right)$, immE: immature erythrocytes $\left(\mathrm{CD} 71^{\text {in }} \mathrm{CD} 235 \mathrm{a}\right)$, matE: mature erythrocytes $\left(\mathrm{CD} 71^{+} \mathrm{CD} 235 \mathrm{a}^{+}\right)$. Bars represent mean $\pm \mathrm{SEM}$. Mann-Whitney test: ${ }^{*} P<0.05, * * P<0.01, * * * P<0.001, * * * * P<0.0001$. 
MCL-1 inhibitor S63845, together with increasing doses of the BCL-XL inhibitor A-1155463. Apoptosis induction was determined $24 \mathrm{~h}$ later (Figure 8A). Using SynergyFinder (https://synergyfinder.fimm.fi) a doseresponse matrix was calculated (Figure $8 \mathrm{~B}$ ). The resulting Bliss score of 21.26 indicates strong synergy between the two inhibitors. Synthetic lethality was confirmed in colony-forming assays, both with cord blood- and bone marrow-derived $\mathrm{CD}^{+} 4^{+}$cells. Already at concentrations of $0.1 \mu \mathrm{M}$ each, the drug combination resulted in a substantial loss of colony-forming cells (compare Figure 8C, $\mathrm{D}$ with Figures $6 \mathrm{~B}, \mathrm{C}$ and 7 ).

To determine the number of immature cells with selfrenewal potential that survived BCL-XL and/or MCL-1 inhibition, we used 10,000 cells isolated from primary colonies for serial colony-forming assays. Interestingly, only BCL-XL inhibition in the first plating resulted in depletion of progenitor cells able to form colonies in the second plating. However, there was a synergistic effect when this BCL-XL inhibition was combined with MCL-1 inhibition (Online Supplementary Figure S5).

\section{Discussion}

Because of the narrow spectrum of cancer entities susceptible to venetoclax, specific MCL-1 and BCL-XI inhibitors are eagerly awaited by oncologists. However, observations made in genetically modified mice indicate that inhibition of MCL-1 or BCL-XL could have more severe side effects than BCL-2 inhibition. Mice deficient for either MCL-1 or BCL-XL have severe developmental phenotypes while BCL-2-deficient mice lack lymphocytes and melanocytes but are otherwise normal. ${ }^{10,40,4}$ Hematopoietic toxicity of anticancer drugs is responsible for most therapy-related morbidity and mortality and a

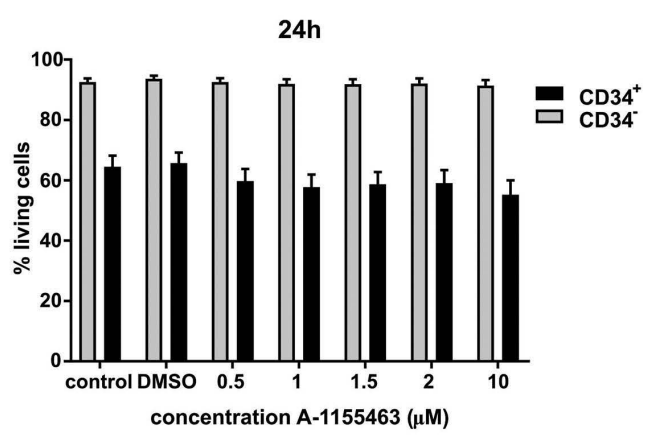

C

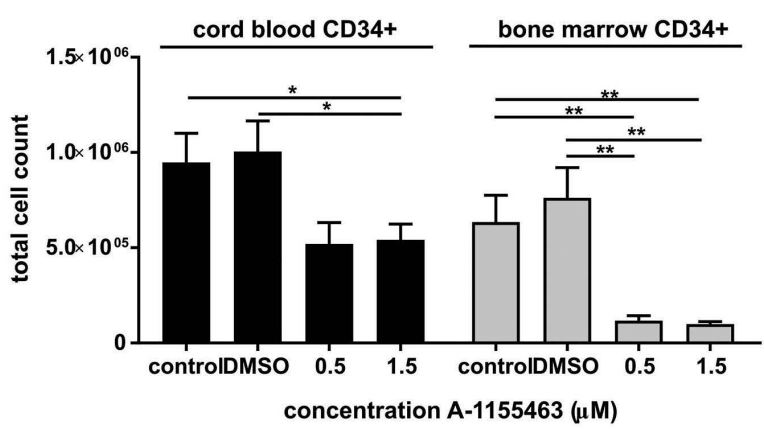

E

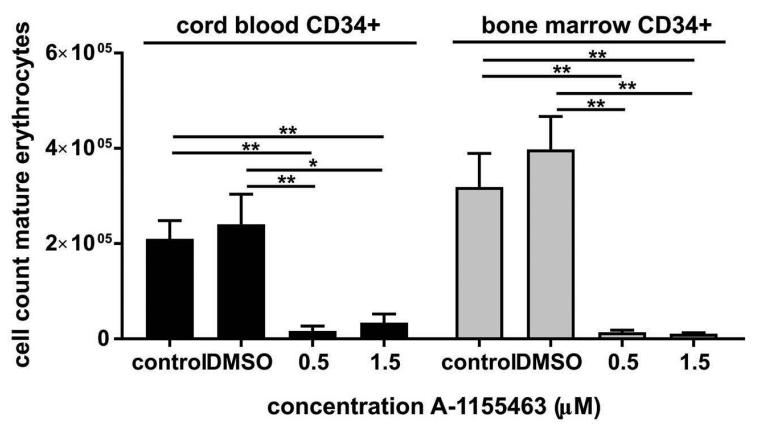

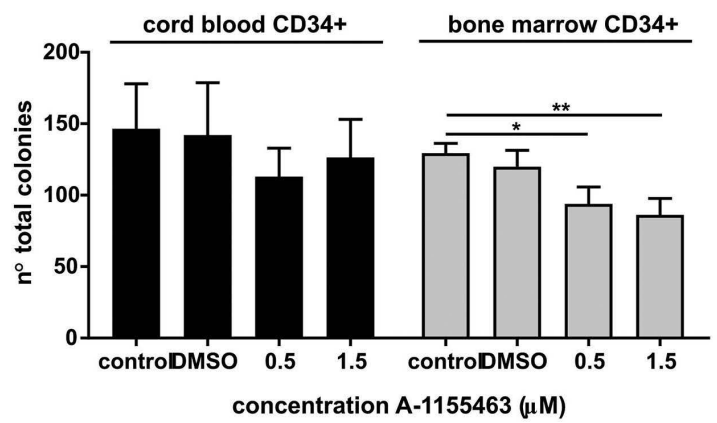

$\mathbf{D}$

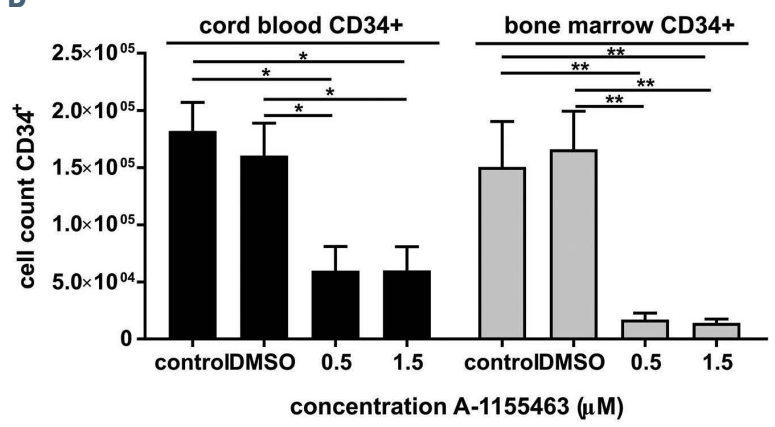

$\mathbf{F}$

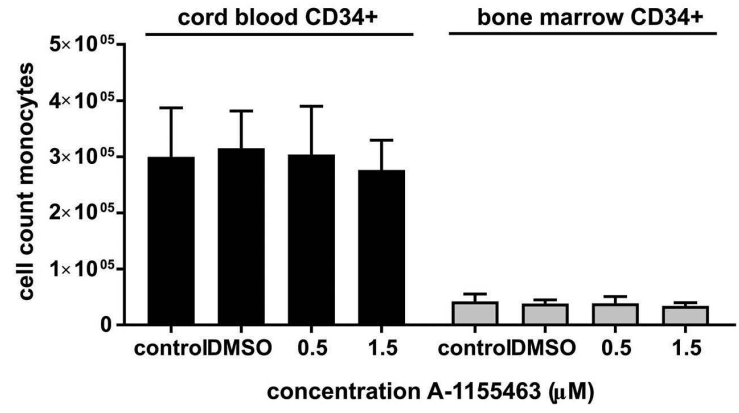

Figure 7. BCL-XL inhibition impedes colony formation and survival of erythroid cells. (A) Freshly isolated bone marrow was subjected to density gradient centrifugation and mononuclear cells were divided into $\mathrm{CD} 34^{+}$and $\mathrm{CD} 34$ cells using magnetic activated cell sorting technology. Both cell fractions were treated with the indicated concentrations of the BCL-XL inhibitor A-1155463. After $24 \mathrm{~h}$, percentages of living cells were determined by flow cytometry using annexin V/7-AAD. Bars represent mean \pm standard error of mean (SEM); $n=3-4$ from four independent experiments. (B-F) Human CD34 ${ }^{+}$cells, either derived from cord blood or bone marrow, were differentiated in MethoCult culture containing 0.5 or $1.5 \mu \mathrm{M}$ A-1155463. As controls, untreated and dimethylsulfoxide (DMSO)-treated cells were used ( $n=6-7$ from seven independent experiments). After 11 days, total colony numbers (B) and total cell numbers (C) were determined using light microscopy and hemocytometry, respectively. Different cell types were determined by flow cytometry, and their absolute cell numbers were calculated (D-F). The following cell types were studied; immature CD34 ${ }^{+}$cells, monocytes (CD34 CD33 ${ }^{+}$CD $14^{+}$CD115) and mature erythrocytes $\left(C D 71^{+}\right.$CD235a $\left.{ }^{+}\right)$. 
common reason for treatment delays or dose reductions. We, therefore, consider it important to generate preclinical data to evaluate the hematotoxicity profile of such novel drugs. Recently, we described the detrimental effects of BCL-XL inhibition on human HSPC and erythroid progenitors. ${ }^{31}$

Here, we dissected the effects of MCL-1 inhibition on different immature and mature types of hematologic cells. By using an RNA interference approach and the specific small molecule inhibitor S63845, we consistently found that MCL-1 expression is crucial for multipotent stem and progenitor cells, as well as for myeloid progenitors, while erythroid progenitors are less susceptible to MCL-1 inhibition. During later stages of blood cell differentiation, MCL-1 becomes dispensable for cell survival. Interestingly, we noted re-expression of $M C L-1$ mRNA after some days of culture, when shRNA \#4 was used, while the shRNA \#3 resulted in stable knockdown. Nevertheless, the resulting phenotypes were strikingly similar indicating that the loss of stem and multipotent progenitors occurs early after MCL-1 depletion and cannot be compensated by later MCL-1 re-expression.

Looking more closely at the stem and progenitor cell compartment, we noted that cells that specifically enter the differentiation process are highly dependent on MCL1 expression, while proliferating CD $34^{+}$cells remain fairly resistant. What is the reason for this difference? It is possible that the differentiation process is associated with increased stress levels reflected by accumulation of activated $\mathrm{BH} 3-$ only proteins. Alternatively, it is possible that the cytokines TPO, FLT3L, SCF and IL3, which induce cell proliferation and are used for $\mathrm{CD} 34^{+}$cell culture, not only induce proliferation but also confer $\mathrm{CD} 34^{+}$cells with survival signals, thereby rendering them independent of MCL-1 expression. Indeed, we have shown earlier that these cytokines induce $B C L-X L$ mRNA upregulation and at the same time repress expression of the pro-apoptotic BCL-2 proteins $B I M$ and $B M F^{30}$ Also in this study, $B I M$ mRNA levels were lower and $B C L-X L$ mRNA levels higher when cells were cultured in the presence of TPO, FLT3L, SCF and IL-3. Delbridge et al. recently showed that MCL-1 expression in murine HSPC is critically required to counteract PUMA-induced apoptosis. While mice lacking only one $\mathrm{Mcl}-1$ allele in the hematopoietic system rapidly succumbed to bone marrow failure, additional deletion of both Puma alleles rescued all animals. ${ }^{26}$ However, our in vitro studies showed strong upregulation of PUMA mRNA in human $\mathrm{CD} 34^{+}$cells irrespective of the
A

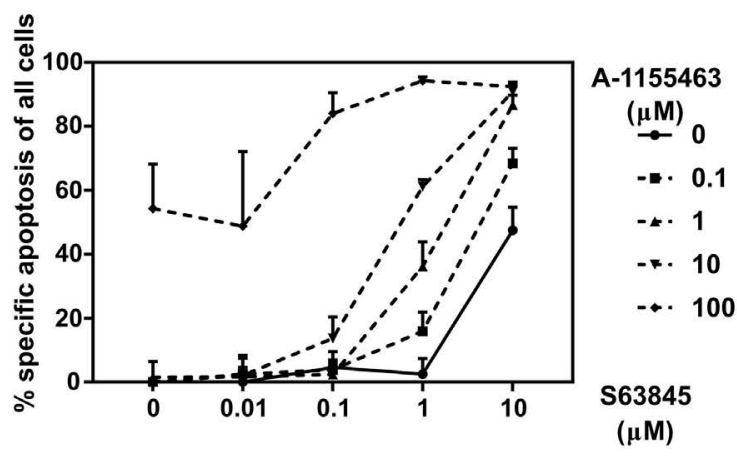

C

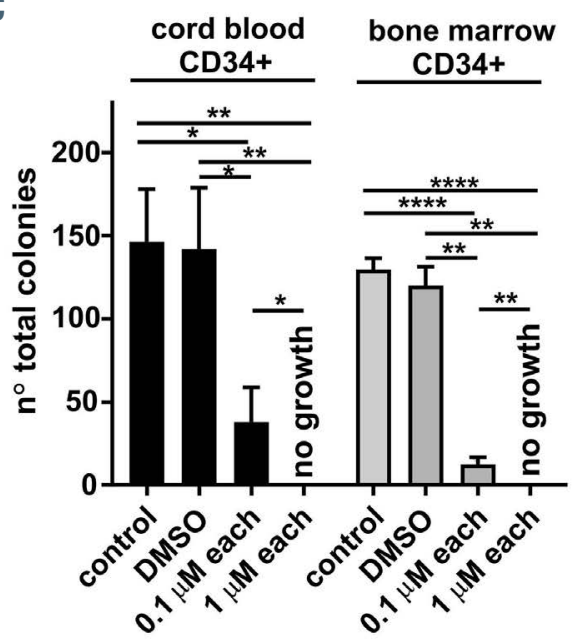

B

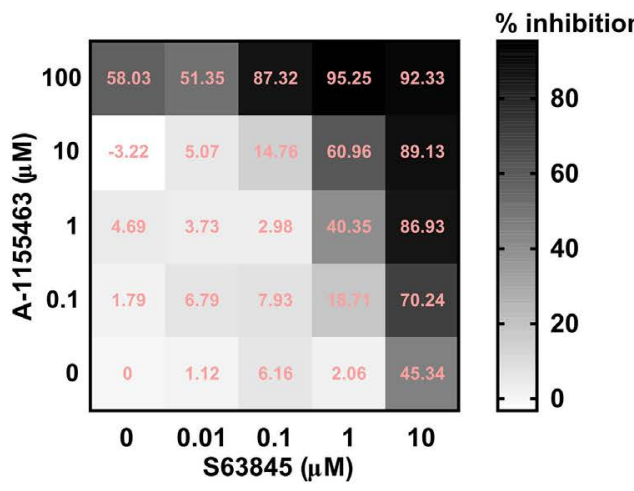

D

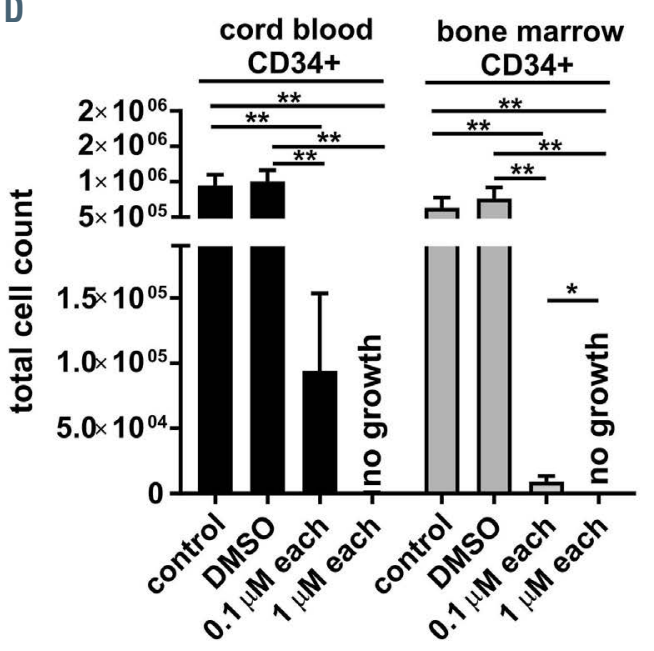

Figure 8. Synergistic action of MCL-1 and BCL-XL inhibitors on human hematopoietic stem and progenitor cells. (A-B) Cord blood CD34 ${ }^{+}$cells were treated with increasing doses of the inhibitors $\$ 63845$ and A-1155463 to determine synergism between the drugs. (A) Apoptosis was measured $24 \mathrm{~h}$ after treatment using annexin V/7-AAD. The percent specific apoptosis was calculated. (B) A dose-response matrix was determined using the web application SynergyFinder ( $\mathrm{n}=4$ from four independent experiments). (C-D) Human CD $34^{+}$cells, derived from either cord blood or bone marrow, were differentiated in MethoCult culture (1,000 cells seeded per plate) in the presence of a combination of the MCL-1 inhibitor S63845 and the BCL-XL inhibitor A-1155463 (0.1 $\mu$ M or $1 \mu \mathrm{M}$ of each). After 10 days, total colony numbers $(C)$ and total cell numbers $(D)$ were determined by light microscopy and hemocytometry, respectively. Bars represent mean \pm standard error of mean; $\mathrm{n}=6-7$ from six independent experiments. Mann-Whitney test: $* P<0.05, * * P<0.01 * * * P<0.001, * * * * P<0.0001$. 
culture conditions and without being reflected by their MCL-1 addiction. This indicates that although there is a conserved role of MCL-1 for survival of murine and human HSPC, its function in human cells might not be restricted to inhibition of PUMA.

We wondered whether also the most immature stem cells, those able to self-renew, depend on MCL-1 expression. While it is one limitation of in vitro model systems that dormant stem cells cannot be analyzed reliably, we were able to show by serial colony-forming assays that cells able to self-renew were dependent on BCL-XL rather than on MCL-1 expression. This is in contrast to findings published by Campbell et al., who attributed the loss of immature stem and progenitor cells upon MCL-1 inhibition to their reduced propensity to self-renew. ${ }^{42}$

While human cord blood-derived HSPC were severely affected by MCL-1 inhibition in our hands, other authors claimed good tolerability of S63845 in non-malignant hematopoietic cells. ${ }^{33-35}$ We hypothesized that this discrepancy was caused by cell-intrinsic differences between cord blood HSPC used in our study and bone marrow HSPC derived from aged persons used in other studies. ${ }^{33}$ We therefore compared CD $34^{+}$cells isolated from cord blood and bone marrow with regards to protein expression of anti-apoptotic BCL-2 proteins and their susceptibility to different BH3-mimetics. Adult HSPC had higher levels of BCL-2. Nevertheless, BCL-2 inhibition had no negative effects on colony-forming potential of aged HSPC. MCL-1 and BCL-XL levels were similar between the two types of HSPC while BFL1/A1 was not expressed. Importantly, inhibition of either MCL-1 or BCL-XL significantly impeded colony formation of both neonatal and adult HSPC and no cell type-specific difference could be noted.

What do our results imply? First, the resistance of mature blood cells to S63845 suggests that immediate hematologic side effects might be mild in patients treated with MCL-1 inhibitors. The depletion of immature progenitor cells can, however, be associated with a relevant risk of severe cytopenias, although these might not occur immediately. To avoid excessive or even permanent bone marrow damage, repeated bone marrow analyses might be useful to detect hypocellularity as early as possible. Second, MCL-1 and BCL-XL inhibitors have synergistic rather than additive effects on human CD34+ HSPC. Synthetic lethality of two BH3-mimetics was shown for multiple tumors: The combination of BCL-2 and MCL-1 inhibitors showed synergistic effects in a vast variety of malignancies, including mantle cell lymphoma, T-cell prolymphocytic leukemia, multiple myeloma, high-risk Bcell acute lymphoblastic leukemia, AML and melanoma. BCL-XL and MCL-1 inhibitors were successfully com- bined in multiple myeloma, melanoma, prostate cancer and multiple pediatric tumors. ${ }^{35,43-50}$ These observations make the combination of different $\mathrm{BH} 3$-mimetics very attractive. However, our results point strongly towards synthetic lethality also in healthy tissues. Specifically, combined BCL-XL and MCL-1 inhibition might be detrimental to healthy hematopoietic tissue. This fact should be kept in mind when new clinical trials are designed.

Most data available so far, including our own, were acquired either in vitro or in artificial mouse models. . $^{33-35,51}$ Clinical data gathered from already initiated phase I trials (e.g., NCT03218683, NCT02675452, NCT03465540, NCT02979366) will provide better insight into both the anticancer efficacy of MCL-1 inhibitors and their frequent side effects. ${ }^{52}$ Importantly, some trials using small molecule MCL-1 inhibitors were placed on hold by the FDA in september 2019 because of cardiac toxicity. ${ }^{53}$ No data on hematologic toxicities have been published yet. Based on the very promising preclinical data ${ }^{28,34,54}$ one could speculate that the overall benefit-to-risk profile of MCL-1 inhibitors will be favorable, especially for tumors otherwise refractory to chemotherapy. In case of severe irreversible hematopoietic damage created by MCL- 1 inhibitors, these compounds could still be used within high-dose chemotherapy regimens given prior to autologous or allogeneic hematopoietic stem cell transplantation.

\section{Disclosures}

No conflicts of interest to disclose.

\section{Contributions}

$S B, S A, J F O, E M D, C M, Y W, J M W$ and VRM designed and performed experiments; $S B, S A, J F O, E M D, Y W$ and $M E$ analyzed and interpreted data; $S B, S A$ and $M E$ wrote the manuscript; $L K, H S$ and MK provided human samples.

\section{Acknowledgments}

We thank the members of the DFG-FOR2036 consortium for insightful discussions, Nora Kaltenbach and Caroline Ambs for excellent technical assistance, the animal care-takers of the Center for Experimental Models and Transgenic Services (CEMT) for animal care and the Lighthouse Fluorescence Technologies Core Facility, Freiburg for cell sorting and maintenance of flow cytometers. We are grateful to Heike Pahl for providing us lentiviral constructs and Albert Gründer for support during initial cloning.

\section{Funding}

This work was supported by grants from the German Academic Exchange Service (DAAD) (funding program 57048249 to SA) and the German Research Foundation (DFGFOR2036, ER599/3-1 and ER599/3-2 to ME).

\section{References}

1. Venclexta FDA Approval History. https://www.drugs.com/history/venclexta.html.

2. Kollek M, Muller A, Egle A, Erlacher M. Bcl2 proteins in development, health, and disease of the hematopoietic system. FEBS J. 2016;283(15):2779-2810

3. Labi V, Erlacher M, Kiessling S, Villunger A. $\mathrm{BH} 3$-only proteins in cell death initiation, malignant disease and anticancer therapy. Cell Death Differ. 2006;13(8):1325-1338.
4. Merino D, Kelly GL, Lessene G, Wei AH, Roberts AW, Strasser A. BH3-mimetic drugs: blazing the trail for new cancer medicines. Cancer Cell. 2018;34(6):879-891.

5. Park CM, Bruncko M, Adickes J, et al. Discovery of an orally bioavailable small molecule inhibitor of prosurvival B-cell lymphoma 2 proteins. I Med Chem. 2008;51(21):6902-6915

6. Oltersdorf T, Elmore SW, Shoemaker AR, et al. An inhibitor of Bcl-2 family proteins induces regression of solid tumours. Nature. 2005;435(7042):677-681.
7. Roberts AW, Seymour JF, Brown JR, et al. Substantial susceptibility of chronic lymphocytic leukemia to BCL2 inhibition: results of a phase I study of navitoclax in patients with relapsed or refractory disease. J Clin Oncol. 2012;30(5):488-496.

8. Wilson WH, O'Connor OA, Czuczman MS, et al. Navitoclax, a targeted high-affinity inhibitor of BCL-2, in lymphoid malignancies: a phase 1 dose-escalation study of safety, pharmacokinetics, pharmacodynamics, and antitumour activity. Lancet Oncol 2010;11(12):1149-1159. 
9. Souers AJ, Leverson JD, Boghaert ER, et al. ABT-199, a potent and selective BCL-2 inhibitor, achieves antitumor activity while sparing platelets. Nat Med. 2013;19(2):202208.

10. Veis DJ, Sorenson CM, Shutter JR, Korsmeyer SJ. Bcl-2-deficient mice demonstrate fulminant lymphoid apoptosis, polycystic kidneys, and hypopigmented hair. Cell. 1993;75(2):229-240.

11. Yamamura K, Kamada S, Ito S, Nakagawa K, Ichihashi M, Tsujimoto Y. Accelerated disappearance of melanocytes in bcl-2-deficient mice. Cancer Res. 1996;56(15):3546-3550

12. Punnoose EA, Leverson JD, Peale F, et al. Expression profile of BCL-2, BCL-XL, and MCL-1 predicts pharmacological response to the BCL-2 selective antagonist venetoclax in multiple myeloma models. Mol Cancer Ther. 2016;15(5):1132-1144.

13. Wuilleme-Toumi S, Robillard N, Gomez P, et al. Mcl-1 is overexpressed in multiple myeloma and associated with relapse and shorter survival. Leukemia. 2005;19(7):12481252.

14. Jayappa KD, Portell CA, Gordon VL, et al. Microenvironmental agonists generate de novo phenotypic resistance to combined ibrutinib plus venetoclax in CLL and MCL. Blood Adv. 2017;1(14):933-946.

15. Birkinshaw RW, Gong JN, Luo CS, et al. Structures of BCL-2 in complex with venetoclax reveal the molecular basis of resistance mutations. Nat Commun. 2019;10(1):2385.

16. Blombery P. Mechanisms of intrinsic and acquired resistance to venetoclax in B-cell lymphoproliferative disease. Leuk Lymphoma. 2020;61(2):257-262.

17. Blombery P, Anderson MA, Gong JN, et al. Acquisition of the recurrent Gly101Val mutation in BCL2 confers resistance to venetoclax in patients with progressive chronic lymphocytic leukemia. Cancer Discov. 2019;9(3):342-353.

18. Herling CD, Abedpour N, Weiss J, et al. Clonal dynamics towards the development of venetoclax resistance in chronic lymphocytic leukemia. Nat Commun. 2018;9(1): 727.

19. Beroukhim R, Mermel CH, Porter D, et al. The landscape of somatic copy-number alteration across human cancers. Nature. 2010;463(7283):899-905.

20. Kozopas KM, Yang T, Buchan HL, Zhou P, Craig RW. MCL1, a gene expressed in programmed myeloid cell differentiation, has sequence similarity to BCL2. Proc Natl Acad Sci U S A. 1993.90(8):3516-3520

21. Bae J, Leo CP, Hsu SY, Hsueh AJ. MCL-1S, a splicing variant of the antiapoptotic BCL-2 family member MCL-1, encodes a proapoptotic protein possessing only the $\mathrm{BH} 3$ domain. J Biol Chem. 2000;275(33):2525525261.

22. Kim JH, Sim SH, Ha HJ, Ko JJ, Lee K, Bae J. MCL-1ES, a novel variant of MCL-1, associates with MCL-1L and induces mitochondrial cell death. FEBS Lett. 2009;583(17):27582764.

23. Perciavalle RM, Stewart DP, Koss B, et al. Anti-apoptotic MCL-1 localizes to the mitochondrial matrix and couples mitochondrial fusion to respiration. Nat Cell Biol.
2012;14(6):575-583

24. Rinkenberger JL, Horning S, Klocke B, Roth $\mathrm{K}$, Korsmeyer SJ. Mcl-1 deficiency results in peri-implantation embryonic lethality. Genes Dev. 2000;14(1):23-27.

25. Opferman JT, Iwasaki H, Ong CC, et al. Obligate role of anti-apoptotic MCL-1 in the survival of hematopoietic stem cells. Science. 2005;307(5712):1101-1104.

26. Delbridge AR, Opferman JT, Grabow S, Strasser A. Antagonism between MCL-1 and PUMA governs stem/progenitor cell survival during hematopoietic recovery from stress. Blood. 2015;125(21):3273-3280

27. Vo TT, Ryan J, Carrasco R, et al. Relative mitochondrial priming of myeloblasts and normal HSCs determines chemotherapeutic success in AML. Cell. 2012;151(2):344-355.

28. Kotschy A, Szlavik Z, Murray J, et al. The MCL1 inhibitor S63845 is tolerable and effective in diverse cancer models. Nature. 2016:538(7626):477-482.

29. Roelz R, Pilz IH, Mutschler M, Pahl HL. Of mice and men: human RNA polymerase III promoter U6 is more efficient than its murine homologue for shRNA expression from a lentiviral vector in both human and murine progenitor cells. Exp Hematol. 2010;38(9):792-797

30. Labi V, Bertele D, Woess C, et al. Haematopoietic stem cell survival and transplantation efficacy is limited by the BH3only proteins Bim and Bmf. EMBO Mol Med. 2013;5(1):122-136.

31. Afreen S, Bohler S, Muller A, et al. BCL-XL expression is essential for human erythropoiesis and engraftment of hematopoietic stem cells. Cell Death Dis. 2020;11(1):8

32. Ianevski A, He L, Aittokallio T, Tang J. SynergyFinder: a web application for analyzing drug combination dose-response matrix data. Bioinformatics. 2020;36 (8):2645.

33. Moujalled DM, Pomilio G, Ghiurau C, et al. Combining BH3-mimetics to target both BCL-2 and MCL1 has potent activity in preclinical models of acute myeloid leukemia. Leukemia. 2019;33(4):905-917.

34. Fiskus W, Cai T, DiNardo CD, et al. Superior efficacy of cotreatment with BET protein inhibitor and BCL2 or MCL1 inhibitor against AML blast progenitor cells. Blood Cancer J. 2019;9(2):4.

35. Ramsey HE, Fischer MA, Lee $T$, et al. A novel MCL1 inhibitor combined with venetoclax rescues venetoclax-resistant acute myelogenous leukemia. Cancer Discov. 2018:8(12):1566-1581.

36. Motoyama N, Wang F, Roth KA, et al. Massive cell death of immature hematopoietic cells and neurons in Bcl-x-deficient mice. Science. 1995;267(5203):1506-1510

37. Motoyama N, Kimura T, Takahashi T, Watanabe T, Nakano T. bcl-x prevents apoptotic cell death of both primitive and definitive erythrocytes at the end of maturation. J Exp Med. 1999:189(11):1691-1698.

38. Delbridge AR, Aubrey BJ, Hyland C, et al. The BH3-only proteins BIM and PUMA are not critical for the reticulocyte apoptosis caused by loss of the pro-survival protein BCL-XL. Cell Death Dis. 2017;8(7):e2914.

39. Roberts AW, Davids MS, Pagel JM, et al.
Targeting BCL2 with venetoclax in relapsed chronic lymphocytic leukemia. N Engl J Med. 2016;374(4):311-322.

40. Nakayama K, Nakayama K, Negishi I, Kuida K, Sawa H, Loh DY. Targeted disruption of Bcl-2 alpha beta in mice: occurrence of gray hair, polycystic kidney disease, and lymphocytopenia. Proc Natl Acad Sci U S A. 1994;91(9):3700-3704.

41. Matsuzaki Y, Nakayama K, Nakayama K, et al. Role of bcl-2 in the development of lymphoid cells from the hematopoietic stem cell. Blood. 1997:89(3):853-862.

42. Campbell CJ, Lee JB, Levadoux-Martin M, et al. The human stem cell hierarchy is defined by a functional dependence on Mcl-1 for self-renewal capacity. Blood. 2010;116(9): 1433-1442.

43. Prukova D, Andera L, Nahacka Z, et al Cotargeting of BCL2 with venetoclax and MCL1 with S63845 is synthetically lethal in vivo in relapsed mantle cell lymphoma. Clin Cancer Res. 2019;25(14):4455-4465.

44. Smith VM, Lomas O, Constantine D, et al. Dual dependence on BCL2 and MCL1 in Tcell prolymphocytic leukemia. Blood Adv. 2020;4(3):525-529.

45. Mukherjee N, Amato CM, Skees J, et al. Simultaneously inhibiting BCL2 and MCL1 is a therapeutic option for patients with advanced melanoma. Cancers (Basel). 2020;12(8):2182 .

46. Abdul Rahman SF, Muniandy K, Soo YK, et al. Co-inhibition of BCL-XL and MCL-1 with selective BCL-2 family inhibitors enhances cytotoxicity of cervical cancer cell lines. Biochem Biophys Rep. 2020;22: 100756

47. Slomp A, Moesbergen LM, Gong JN, et al. Multiple myeloma with 1q21 amplification is highly sensitive to MCL-1 targeting. Blood Adv. 2019;3(24):4202-4214.

48. Algarin EM, Diaz-Tejedor A, Mogollon P, et al. Preclinical evaluation of the simultaneous inhibition of MCL-1 and BCL-2 with the combination of $\mathrm{S} 63845$ and venetoclax in multiple myeloma. Haematologica. 2020;105(3):e116-e120.

49. Lee EF, Harris Tा, Tran S, et al. BCL-XL and MCL- 1 are the key BCL-2 family proteins in melanoma cell survival. Cell Death Dis. 2019;10(5):342.

50. Arai S, Jonas $\mathrm{O}$, Whitman MA, Corey $\mathrm{E}$ Balk SP, Chen S. Tyrosine kinase inhibitors Increase MCL1 degradation and in combination with BCLXL/BCL2 inhibitors drive prostate cancer apoptosis. Clin Cancer Res. 2018:24(21):5458-5470.

51. Brennan MS, Chang C, Tai L, et al Humanized Mcl-1 mice enable accurate preclinical evaluation of MCL-1 inhibitors destined for clinical use. Blood. 2018;132(15): 1573-1583.

52. Hird AW, Tron AE. Recent advances in the development of Mcl-1 inhibitors for cancer therapy. Pharmacol Ther. 2019;198:59-67.

53. www.ashclinicalnews.org; last accessed Nov 1, 2019

54. Tron AE, Belmonte MA, Adam A, et al. Discovery of Mcl-1-specific inhibitor AZD5991 and preclinical activity in multiple myeloma and acute myeloid leukemia. Nat Commun. 2018;9(1):5341. 